\title{
A Review of the Integrated Design and Control of Electrified Vehicles
}

\author{
Caiyang Wei ${ }^{1, *(\mathbb{D}}$, Theo Hofman ${ }^{1} \mathbb{D}$, Esin Ilhan Caarls ${ }^{2}$ and Rokus van Iperen ${ }^{2}$ \\ 1 Department of Mechanical Engineering, Eindhoven University of Technology, P.O. Box 513, \\ 5600 MB Eindhoven, The Netherlands; t.hofman@tue.nl \\ 2 Bosch Transmission Technology, Postbus 500, 5000 AM Tilburg, The Netherlands; \\ Esin.IlhanCaarls@nl.bosch.com (E.I.C.); Rokus.vanIperen@nl.bosch.com (R.v.I.) \\ * Correspondence: c.wei.1@tue.nl; Tel.: +31-40-247-8325
}

Received: 1 September 2020; Accepted: 3 October 2020; Published: 19 October 2020

check for updates

\begin{abstract}
From a control perspective, the energy management system and the thermal management system of an electrified vehicle are often developed separately, which may not yield the optimal solution. Moreover, an optimal system design requires concurrent plant (topology and size) and controller optimization, which should apply to both energy and thermal domains. This paper originally provides a comprehensive analysis of design and control optimization layers to reveal the interconnections between them and how they influence the optimality of an electrified vehicle design considering both energy and thermal domains. It was found that energy and cost savings can be achieved by integrating these optimization layers, and the energy and thermal domains with four coordination schemes, namely, sequential, iterative, nested and simultaneous. There is a trade-off between optimality, causality, complexity and computational time. Additionally, future research directions in terms of reducing energy consumption and system costs of electrified vehicles are identified herein, such as using integrated design and control methods, employing electrified actuators, exchanging heat between powertrain components and utilizing waste heat recovery systems.
\end{abstract}

Keywords: electrified vehicle; energy management; thermal management; topology optimization; component sizing; rule-based control; optimization-based control

\section{Introduction}

Powertrain electrification plays a crucial role in reducing the unsustainable consumption of natural resources to tackle energy and environmental issues. To fulfill the potential of an electrified vehicle, it is important to develop an energy management system (EMS). The main goal of the EMS is to maximize powertrain efficiency, by optimizing the power flow, through means such as the power split between the internal combustion engine (ICE) and the battery in a parallel hybrid electric vehicle (HEV). While electrified powertrains bring opportunities of improving energy efficiency, due to added heat source components and distinct driving modes, they introduce complexities to the associated thermal management systems (TMSs) [1,2]. A TMS is essential to maintaining powertrain components at predefined temperatures to guarantee efficiency, comfort, safe operation and reliability. Earlier works have shown that a TMS has a significant impact on the energy consumption of an electrified vehicle, e.g., heating, ventilation, and air conditioning (HVAC) [3,4]. The EMS and the TMS of an electrified powertrain were often treated independently in previous studies, as shown in Figure 1. In this scheme, the TMS requests a certain amount of power from the EMS, but whether the control decision of the TMS is energy beneficial is not verified by the EMS. It may not yield the optimal solution [5]. Therefore, it is imperative to integrate these two systems. 


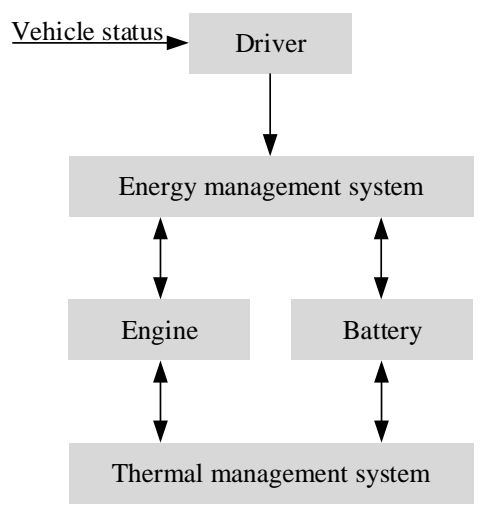

Figure 1. Separate energy and thermal management.

The EMS and the TMS are referred to as control algorithms, which are often developed for fixed configurations and parameters [6,7]. However, an optimal system demands combined design and control optimization, taking into account the coupling between the physical system and the control strategy [8]. In principle, there are three optimization layers for designing an electrified vehicle, including topology, size and control optimization [9]. Hence, these optimization layers should apply to both energy and thermal domains. In this respect, the thermal domain was usually not considered in previous research, which may not arrive at an optimal solution. For instance, different powertrain configurations would require distinct thermal management topologies.

As far as the coupling between the plant (topology and size) and the controller is concerned, there are generally four coordination schemes, including sequential, iterative, nested and simultaneous [8], as demonstrated in Figure 2. Sequential indicates that the dependency between the plant and the controller is not taken into consideration, and the controller is developed for a fixed plant, where only the operational cost (e.g., fuel consumption) is considered. Iterative means that the plant that determines the component cost (e.g., battery price) is first designed, and the controller that determines the operational cost is built based on the given plant. The loop repeats until the coupled variables converge. Nested implies that the controller is optimized for each evaluation of the plant. Simultaneous represents that the plant and the controller are optimized simultaneously. From an energy perspective, an iterative coordination scheme to solve a combined topology and size optimization problem is proposed for double planetary gear (PG) hybrid powertrains in [10], but the thermal domain is not taken into consideration. The thermal response and power consumption of the cooling system and its sizing of a series HEV were investigated in [11] with a sequential approach; however, the energy aspect has yet to be considered. Based on the current literature, a systematic way to analyze and to link those optimization layers for electrified powertrains has yet to be established, in consideration of both energy and thermal aspects.

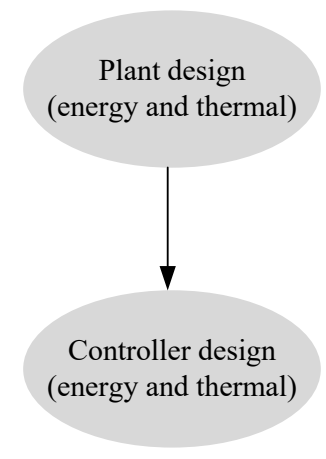

Sequential
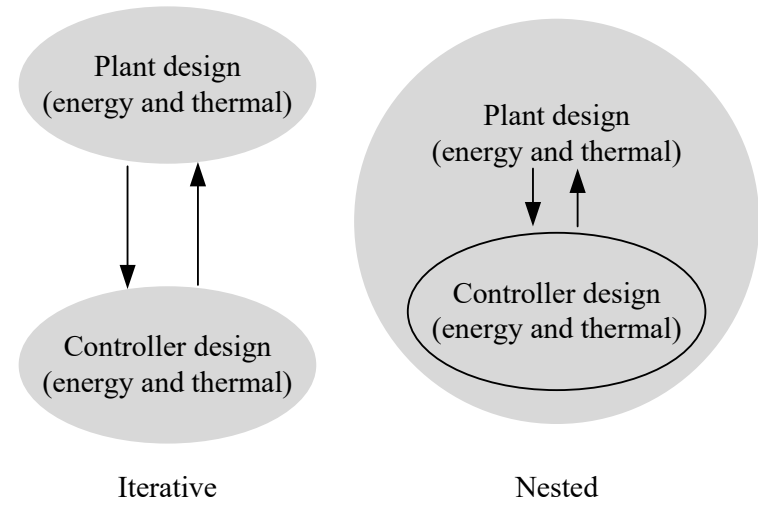

Nested

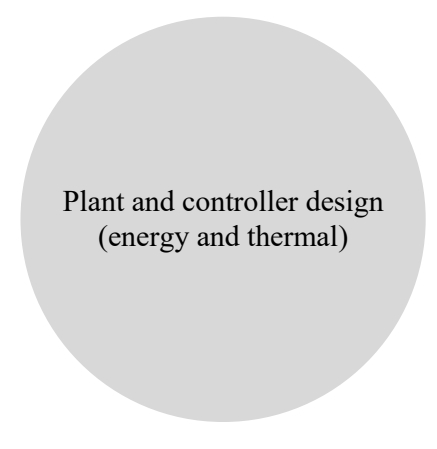

Simultaneous

Figure 2. Coordination schemes between the plant and the controller. 
Energy-efficient and cost-effective electrified powertrains, however, demand a holistic and integrated approach to synthesize design and control aspects in consideration of both energy and thermal domains. Motivated by the above discussion, this study originally provides a comprehensive overview of those optimization layers and coordination methods for electrified vehicles considering both energy and thermal aspects. The main contributions of this paper can be summarized as follows. First, with updated literature, from an energy perspective, we summarize the general problem of combined topology, size and control optimization of electrified powertrains and introduce that to the thermal domain, and show how they are connected mathematically. Second, we classify and survey energy and thermal management systems for electrified vehicles, which only started to appear recently, to highlight the importance of integration. Finally, we identify potential research directions of combined optimal design and control optimization of electrified powertrains, taking into account both energy and thermal aspects. The remainder of this paper is organized as follows. Section 2 analyzes the optimization layers and coordination schemes from an energy perspective, which are investigated from a thermal viewpoint in Section 3. Recent energy and thermal management systems proposed in the literature are discussed in detail in Section 4. Section 5 presents opportunities found for future developments. Finally, conclusions are drawn in Section 6.

\section{Energy-Aware Design and Control Optimization}

If a system is optimized from an energy point of view, e.g., identifying an optimal powertrain configuration with optimized component sizes and power flow, neglecting the thermal domain, it is said to have an energy-aware design and control optimization.

Normally, a design process starts with choosing an architecture to focus on. A configuration that defines the connections between components influences efficiency, cost, comfort, performance, complexity and durability. The best topology can be identified with the lowest total-cost-of-ownership (TCO), consisting of operational costs, e.g., the battery energy consumption, and component costs, such as the engine price, subject to various constraints, for example, performance requirements. The operational costs are related to the control algorithm, for instance, how the battery is used, and the component costs are associated with the component size, e.g., the electric machine size in $\mathrm{kW}$. Topology optimization is therefore often coupled with the control and size layers [12]. Additionally, for a given vehicle architecture, there is a strong dependency between the size and control layers. For example, the battery would be used differently depending on the battery size of an electrified powertrain. Compared to a blended strategy, a larger battery is needed when employing a rule-based (RB) one [13].

\subsection{Topology Generation}

This study mainly focuses on the most common electrified powertrains (e.g., with engine and electric machine(s)), as depicted in Figure 3, including series, parallel and series-parallel (power-split) hybrids. In a series hybrid, the engine is not directly connected to the wheels, which can be controlled to operate efficiently [14], yet it needs a larger battery and electric machine, compared to a parallel hybrid. A parallel hybrid eliminates the need for conversion of engine mechanical power to electrical power, but the engine cannot operate in its most efficient way. Despite complexity, power-split hybrids with PGs combine the advantages of series and parallel hybrids due to added control freedom, and an increasing number of vehicles (e.g., Toyota Prius and Highlander) use this configuration. In Figure 3 , the engine (ICE) mode indicates when only the engine is utilized to drive the wheels. The charging $(\mathrm{CH})$ mode represents that the engine not only propels the vehicle, but also charges the battery. The electric vehicle (EV) mode reflects that the electric machine is the only power source to drive the wheels. The motor assist (MA) mode means when the electric machine is used to support the engine to satisfy the propulsion power. The brake energy recuperation (BER) mode is a mode wherein the braking 
energy is recovered, which is eventually stored in the battery. Selecting a suitable architecture is essential, as it influences efficiency and cost. Topology generation can be formulated as follows:

$$
\begin{aligned}
\text { Generate } & \boldsymbol{T}_{\mathrm{e}}^{f} \subseteq \boldsymbol{T}_{\mathrm{e}}^{p} \\
\text { s.t. } & g_{e}\left(\boldsymbol{T}_{\mathrm{e}}^{f}\right) \leq 0,
\end{aligned}
$$

where subscript $e$ represents the energy domain, $T_{\mathrm{e}}^{f}$ the feasible architectures, $T_{\mathrm{e}}^{p}$ the possible configurations and $g_{e}\left(\boldsymbol{T}_{\mathrm{e}}^{f}\right)$ the constraints-for example, certain connections between powertrain components are needed in order to realize a hybrid functionality, which are used to eliminate infeasible topologies.

In reality, an HEV configuration is typically chosen based on expert knowledge, taking into account, for example, application, component availability and the market trend. It is obvious that the selected topology $\boldsymbol{T}_{\mathrm{e}}^{f}$ is likely not optimal due to limited options $\boldsymbol{T}_{\mathrm{e}}^{p}$. As reported in [15], for power-split hybrids with one PG, among all possible architectures, small design changes can bring about significant cost and energy benefits; Toyota Prius and Chevy Volt were modified into Prius ${ }^{+}$and Volt $^{-}$. It should be noted that in this study, the design space is still small; i.e., there are only 12 possible configurations for power-split hybrid powertrains with a single PG, which makes enumeration of topologies possible. When the design space is large, however, it is intractable, as exploring feasible architectures is combinatorial in nature. Therefore, a systematic and efficient way is required to evaluate all possible topologies. In this context, automatic topology generation that aims to find feasible architectures is emerging [16,17]. For power-split hybrids with multiple PGs, clutches and brakes, automated modeling techniques are being developed, which capture the fundamental dynamics of the vehicle based on physics to represent modes and configurations [16]. Subsequently, various constraints, such as kinematics, complexity and redundancy constraints, can be utilized to eliminate infeasible topologies. In [17], a bond graph was used to represent an architecture and constraints were employed to arrive at feasible configurations. However, these studies are limited to power-split hybrids with multiple PGs. For a predefined set of 16 components, feasible series, parallel and series-parallel hybrid topologies were found in [18], by using constraint logic programming, which automatically generated all possible HEV architectures efficiently and in a structured way. Specifically, each component was a node of an undirected connected finite graph that represented an architecture. Afterwards, functionality and cost constraints were applied, essentially a screening process, to filter out infeasible configurations. Functionality constraints mean that, for instance, to realize hybrid functions, certain connections between components are required. Cost constraints indicate that component redundancy is restricted. Finally, based on the predefined set of 16 powertrain components, the initial search space of $5.7 \times 10^{45}$ possible topologies was reduced to 4779 feasible topologies in less than $5 \mathrm{~min}$. However, the feasible configurations have yet to be assessed based on TCO and vehicle performance, by integrating with control and size layers. 


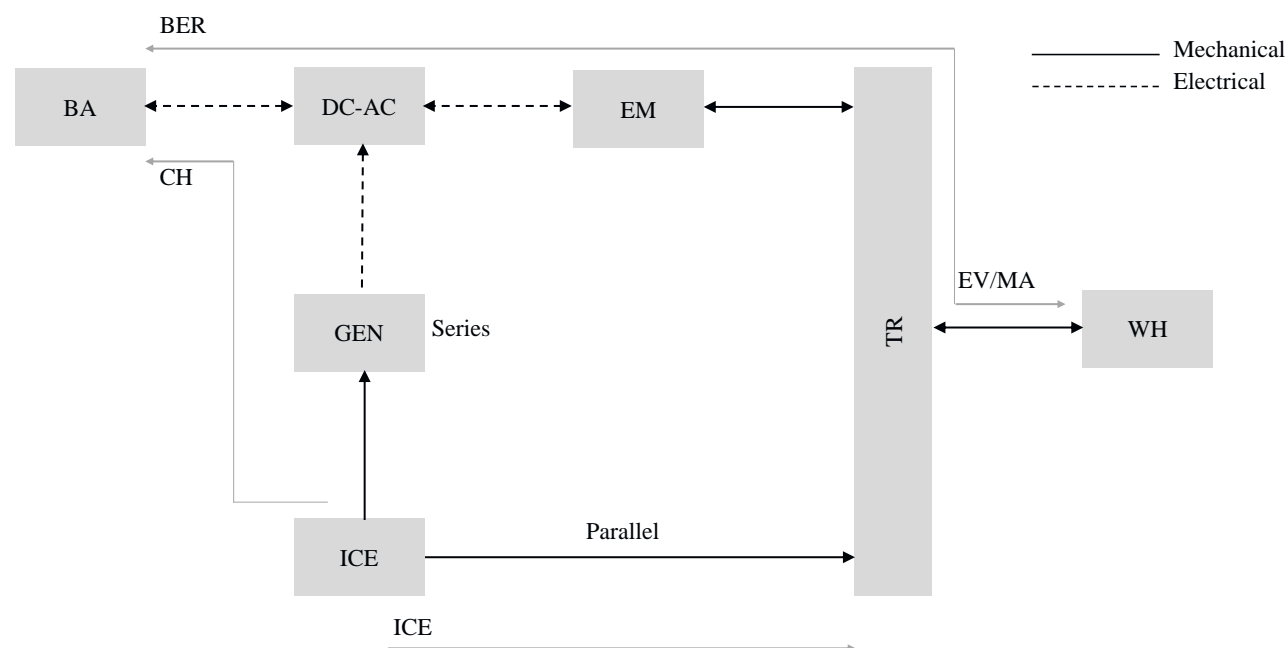

Figure 3. Common electrified powertrain architectures, where BA represents the battery, DC-AC the DC (direct current) to AC (alternating current) inverter, GEN the generator, TR the transmission, WH the wheel, ICE the engine only mode, $\mathrm{CH}$ the charging mode, EV the electric vehicle mode, MA the motor assist mode and BER the brake energy recuperation mode. The series and parallel HEVs are indicated with "series" and "parallel." The main powertrain components are shown as blocks connected via bi-directional mechanical (solid) and electrical (dashed) energy flows.

\subsection{Control Optimization}

In this respect, earlier works mainly focused on the control layer for a given architecture $T_{\mathrm{e}}^{f}$ generated by (1a) and fixed powertrain parameters represented by $s_{\mathrm{e}}$. The main objective of the controller (EMS) is to determine the power flow of the electrified powertrain in an optimal manner so that the energy efficiency is maximized, such as the torque split between the engine and the electric machine in a parallel HEV. For a known drive cycle starting at $t_{0}$ and ending at $t_{\mathrm{f}}$, the EMS aims to find the optimal control variables to minimize a cost function $J_{\mathrm{e}}$, for example, fuel consumption of an HEV, given by

$$
\begin{array}{ll} 
& J_{\mathrm{e}}\left(x_{\mathrm{e}}(t), u_{\mathrm{e}}(t), t \mid\left(T_{\mathrm{e}}^{f}, s_{\mathrm{e}}\right)\right)=\int_{t_{0}}^{t_{\mathrm{f}}} P_{\mathrm{e}}\left(x_{\mathrm{e}}(t), u_{\mathrm{e}}(t), t\right) \mathrm{d} t \\
\text { s.t. } & \dot{x}_{\mathrm{e}}(t)=f\left(x_{\mathrm{e}}(t), u_{\mathrm{e}}(t), t\right) \\
& h_{\mathrm{e}}\left(x_{\mathrm{e}}(t), u_{\mathrm{e}}(t), t\right)=0 \\
& g_{\mathrm{e}}\left(x_{\mathrm{e}}(t), u_{\mathrm{e}}(t), t\right) \leq 0 \\
& x_{\mathrm{e}}\left(t_{\mathrm{f}}\right)=x_{\mathrm{e}}\left(t_{0}\right)
\end{array}
$$

where $x_{\mathrm{e}}$ denotes the vector of state variables. Equation (2b) denotes the energy dynamics of the system, for instance, the state of charge of the battery. $u_{\mathrm{e}}$ denotes the control inputs-e.g., the power sharing between the engine and the battery, $h_{\mathrm{e}}(\cdot)$ the equality constraints, for example, the power balance of the vehicle, $g_{\mathrm{e}}(\cdot)$ the inequality constraints, such as the torque limits of the electric machine (EM),

$$
\tau_{\mathrm{m}, 0}(t) \in\left[\underline{\tau}_{\mathrm{m}, 0}\left(w_{\mathrm{m}}(t)\right), \bar{\tau}_{\mathrm{m}, 0}\left(w_{\mathrm{m}}(t)\right)\right] .
$$

Equation (2e) constrains the dynamic states, such as charge sustaining.

This problem can be solved by two main categories of methods: RB and optimization-based (OB), as illustrated in Figure 4. A thermostat control (TC) strategy was used in [19] for a series $\mathrm{HEV}$, which aimed to maintain the state of charge of the battery within its predefined boundaries, by turning the engine on/off. For a series HEV, a power follower (PF) control strategy is presented in [20], where the engine is the primary source of power to meet the propulsion load and the state 
of charge is midway between its predetermined upper and lower limits. In [21], fuzzy logic (FL) is utilized to decide the power sharing between the battery and the engine of a power-split HEV to improve the fuel economy, by using preestablished rules that are implemented in a map-based format. $\mathrm{RB}$ approaches generally use a set of rules, e.g., if-then conditions, derived from engineering intuition, to make decisions, e.g., letting power sources operate in their efficient regions. These strategies are easy to implement and computationally efficient. However, the rules are often configuration and cycle-dependent. In addition, they require tuning of many parameters and cannot obtain the optimal solution [22].

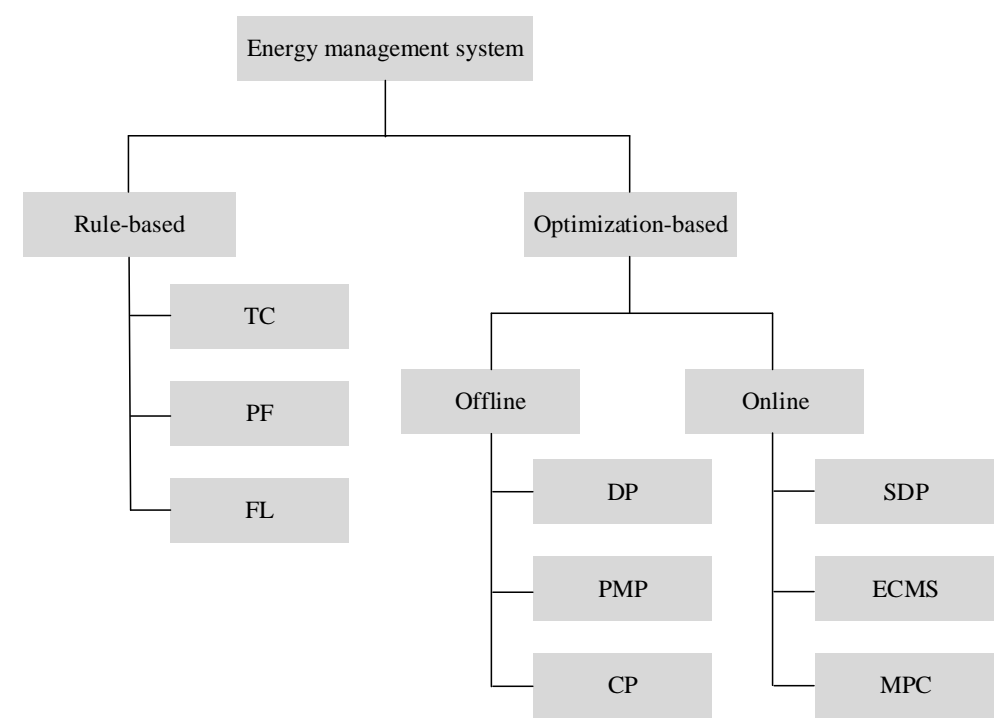

Figure 4. Energy management strategies, where TC represents thermostat control, PF power follower, FL fuzzy logic, DP dynamic programming, PMP Pontryagin's minimum principle, CP convex programming, ECMS equivalent consumption minimization strategy, SDP stochastic dynamic programming and MPC model predictive control.

These drawbacks necessitate the development of optimal controllers. OB methods can be categorized into offline and online algorithms. Dynamic programming (DP), which uses Bellman's principle of optimality, is widely adopted for handling non-linear constraints and finding a globally optimal solution [23], where component models are represented by static maps based on measurements. DP requires a backward-facing powertrain model; i.e., the drive cycle is given in advance. The optimal control sequence is found using an exhaustive search. Its computation time increases exponentially with the number of states and control variables. To reduce the computation time, Pontryagin's minimum principle (PMP) is applied to a power-split HEV [24], as it evaluates second-order differential equations. Under reasonable assumptions, the optimal power split is obtained by finding an appropriate costate for battery power consumption. However, tuning of equivalent parameters is not straightforward, which is sensitive to drive cycle characteristics, especially in the presence of multiple states. Moreover, it is challenging to use PMP to solve problems with complex constraints. To overcome these limitations, convex programming (CP) was used in [25] for a parallel HEV to minimize the fuel consumption, which reduced the computation time and increased the solution robustness, by taking advantage of fast and reliable solvers. It simplified the search for the solution. $\mathrm{CP}$ enables optimization of problems with many dynamic states. However, it requires the optimization problem and component models to be convex. The solution optimality may be compromised due to model simplifications. These offline optimization strategies demand that the driving condition is known a priori, which is not implementable.

This disadvantage motivated the development of online controllers, which use forward-facing models; i.e., the future driving profile is not required. To tackle the implementation issue of DP, stochastic dynamic programming (SDP) was developed for a power-split HEV to optimize the fuel 
economy, which replaces the disturbance with a random Markov process and enables real-time implementation [26]. The quality of solution may be reduced though. The equivalent consumption minimization strategy (ECMS) is used in real-time control of a parallel HEV to minimize the fuel consumption, which translates the battery electricity into its equivalent fuel cost using an equivalence factor [27]. ECMS can be regarded as the online counterpart of PMP, and they have almost the same structure, i.e., with the equivalence factors being the co-states. However, it may lose optimality, since ECMS is derived using PMP conditions. Due to the inherent robustness against model uncertainties, model predictive control (MPC) which is capable of predicting the future driving conditions, is used to solve the energy management problem of a power-split HEV online [28]. The MPC problem can be formulated as a convex optimization problem. The advantages and disadvantages of the foregoing energy management strategies are summarized in Table 1 . Note that some algorithms are combined due to similar characteristics.

Table 1. Advantages and disadvantages of energy management strategies.

\begin{tabular}{llll}
\hline Strategy & Main Advantages & Main Disadvantages & Application \\
\hline Rule-based [19-21] & Easy to implement & $\begin{array}{l}\text { Tuning of many parameters } \\
\text { Cycle- and configuration-dependent rules }\end{array}$ & Series and power-split HEV \\
\hline DP [23] & $\begin{array}{l}\text { Handling complex constraints } \\
\text { Global optimal }\end{array}$ & $\begin{array}{l}\text { Limited states and control variables } \\
\text { Long computation time }\end{array}$ & Powers-split HEV \\
\hline CP [25] & $\begin{array}{l}\text { Low computation time } \\
\text { Handling many states and control variables }\end{array}$ & Problem formulation in convex form & Parallel HEV \\
\hline ECMS [27] & $\begin{array}{l}\text { Real-time control } \\
\text { Single objective }\end{array}$ & $\begin{array}{l}\text { Equivalence factor sensitive to cycle } \\
\text { Sub-optimal }\end{array}$ & Parallel HEV \\
\hline MPC [28] & $\begin{array}{l}\text { Predictive and adaptive } \\
\text { Real-time implementation }\end{array}$ & Sensitive to model quality and prediction horizon & Power-split HEV \\
\hline
\end{tabular}

It should be noted that all these energy management strategies were developed for given design parameters. For a fixed vehicle configuration, however, the powertrain component size, e.g., the battery size, affects the control decision, e.g., the torque split between the engine and the EM, and vice versa. Previous studies have reported that energy efficiency can be improved remarkably by integrating the control and size layers $[29,30]$. Moreover, the component size influences the system cost and performance. To obtain better designs, the size layer should be included.

\subsection{Combined Size and Control Optimization}

Generally, there are two ways to size the components, i.e., RB and OB strategies, as demonstrated in Figure 5. RB approaches based on experience and simple calculations often fail in view of optimality and large numbers of plant variables [31,32]. OB algorithms in this regard can be classified into derivative-free and gradient-based methods.

Dividing rectangles (DIRECT), as a sampling derivative-free algorithm, is used to find the sizes of the battery, EM and engine of a series HEV to minimize the fuel consumption [33]. DIRECT gives equal weights to global and local searches and can handle a discontinuous objective function, equality and inequality constraints. Simulated annealing (SA), as a stochastic global search algorithm, by analogy with the annealing process of metals, is applied to find the optimal sizes of the engine, EM, battery and final drive of a parallel HEV to minimize the TCO [34]. A new solution is only accepted when satisfying the Boltzmann criterion, where the temperature depends on the number of iterations. To minimize the fuel consumption and emissions of a parallel HEV, the genetic algorithm (GA), as an evolutionary algorithm, inspired by the process of natural selection, is utilized to identify the maximum engine power, maximum EM power, battery capacity and final drive ratio [35]. The best candidates are chosen based on the fitness value (objective), and there is a trade-off between computation time and accuracy. Particle swarm optimization (PSO), which iteratively improves a candidate solution, by moving particles towards the best known positions in the search space, is developed for finding the optimal component sizes of a parallel HEV to minimize the TCO [36]. It can handle optimization problems with large search space and complex objective functions. However, PSO does not guarantee 
that an optimal solution is found. Sequential quadratic programming (SQP), as a gradient-based algorithm, which is an iterative method for constrained nonlinear optimization, is used to solve the sizing problem of a parallel HEV to minimize the TCO [37]. However, it is challenging to utilize SQP for large problems with many variables or constraints. CP is used to find the optimal sizes of a parallel HEV to minimize the TCO, by reformulating the optimization problem and powertrain model in convex form [30]. The advantages and disadvantages of the foregoing sizing strategies are summarized in Table 2.

The main goal of a combined size and control method is to find the optimal set-point of the power source to increase the energy efficiency and the optimal component sizes to reduce the powertrain cost, by minimizing

$$
\begin{array}{ll} 
& J_{\mathrm{e}}\left(s_{\mathrm{e}}, x_{\mathrm{e}}(t), u_{\mathrm{e}}^{s}(t), t \mid T_{\mathrm{e}}^{f}\right)=T C O_{\mathrm{e}} \\
& =\int_{t_{0}}^{t_{\mathrm{f}}}\left[\beta P_{\mathrm{f}}\left(s_{\mathrm{e}}, x_{\mathrm{e}}(t), u_{\mathrm{e}}^{s}(t), t\right)+\gamma P_{\mathrm{b}}\left(s_{\mathrm{e}}, x_{\mathrm{e}}(t), u_{\mathrm{e}}^{s}(t), t\right)\right] \mathrm{d} t+C_{\mathrm{e}}\left(s_{\mathrm{e}}\right) \\
\text { s.t. } & \dot{x}_{\mathrm{e}}(t)=f\left(s_{\mathrm{e}}, x_{\mathrm{e}}(t), u_{\mathrm{e}}^{s}(t), t\right) \\
& h_{\mathrm{e}}\left(s_{\mathrm{e}}, x_{\mathrm{e}}(t), u_{\mathrm{e}}^{s}(t), t\right)=0 \\
& g_{\mathrm{e}}\left(s_{\mathrm{e}}, x_{\mathrm{e}}(t), u_{\mathrm{e}}^{s}(t), t\right) \leq 0 \\
& s_{\mathrm{e}} \in\left[\underline{s}_{\mathrm{e}}, \bar{s}_{\mathrm{e}}\right] \\
& x_{\mathrm{e}}\left(t_{\mathrm{f}}\right)=x_{\mathrm{e}}\left(t_{0}\right)
\end{array}
$$

where $s_{\mathrm{e}}$ represents the design parameters, e.g., the EM size, $\beta$ the price of gasoline, $P_{\mathrm{f}}$ the fuel power, $\gamma$ the price of electricity, $P_{\mathrm{b}}$ the battery power and $C_{\mathrm{e}}$ the powertrain cost-e.g., the battery price $C_{\mathrm{b}}$, which depends on the battery size represented by a scaling factor $s_{b}$ [38], i.e.,

$$
C_{\mathrm{b}}=C_{\mathrm{b}, 0}+s_{\mathrm{b}} C_{1}
$$

where $C_{\mathrm{b}, 0}$ is the initial battery cost and $C_{1}$ the linear cost coefficient. As an example, referring to (3), the component size influences the control strategy in the sense that

$$
\tau_{\mathrm{m}}(t) \in s_{\mathrm{m}}\left[\underline{\tau}_{\mathrm{m}, 0}\left(w_{\mathrm{m}}(t)\right), \bar{\tau}_{\mathrm{m}, 0}\left(w_{\mathrm{m}}(t)\right)\right],
$$

where $s_{\mathrm{m}}$ is the scaling factor for the EM. Therefore, the control input $\boldsymbol{u}_{\mathrm{e}}$ in (2a) is changed to $\boldsymbol{u}_{\mathrm{e}}^{s}$ in (4a) due to the influence of design parameters $s_{\mathrm{e}}$ introduced, which is reflected by the superscript $s$.

Theoretically, the combination of the size layer from Figure 5 and the control layer from Figure 4 yields different solution methods to (4a), which are connected with the four coordination schemes, as shown in Figure 2.

Table 2. Advantages and disadvantages of sizing strategies.

\begin{tabular}{lll}
\hline Strategy & Main Advantages & Main Disadvantages \\
\hline Rule-based [31,32] & Relatively simple calculations & $\begin{array}{l}\text { Non-optimal } \\
\text { Cycle- and configuration-dependent sizes }\end{array}$ \\
\hline Derivative-free [33-36] & $\begin{array}{l}\text { Handling large design space } \\
\text { Handling complex functions and constraints }\end{array}$ & $\begin{array}{l}\text { Tuning of parameters } \\
\text { Large number of function evaluations } \\
\text { No guarantee of an optimal solution }\end{array}$ \\
\hline Gradient-based [30,37] & Low computation time & $\begin{array}{l}\text { Constraint handling } \\
\text { Convex formulation }\end{array}$ \\
\hline
\end{tabular}




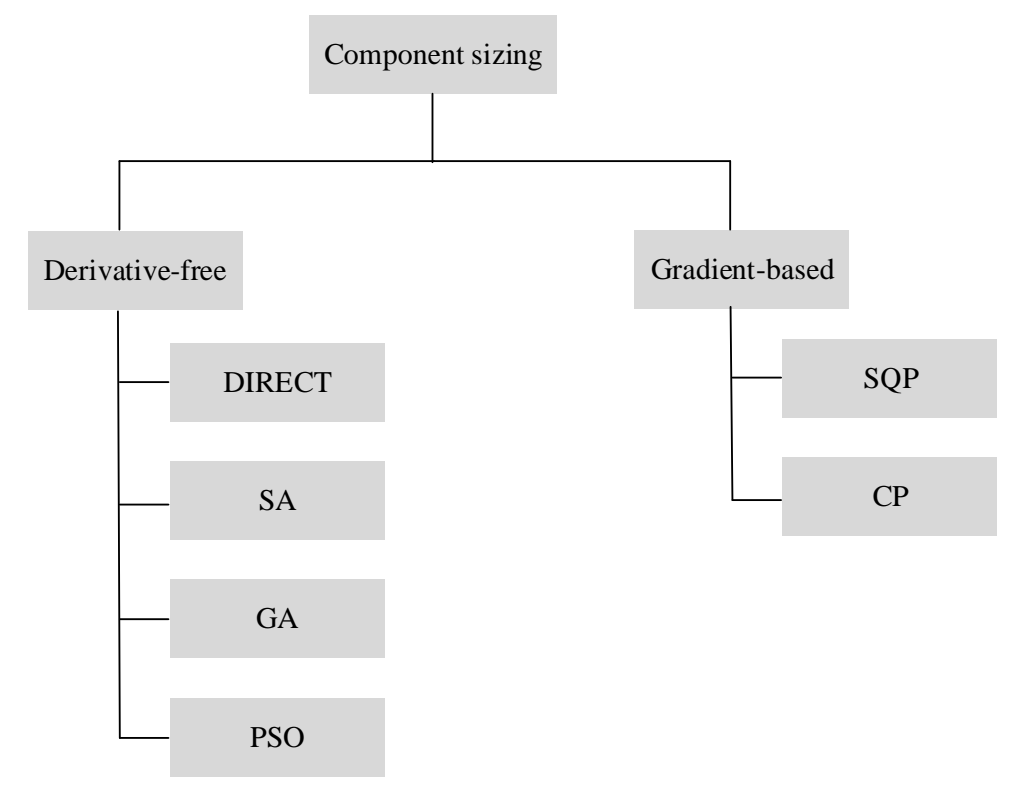

Figure 5. Component sizing strategies, where DIRECT represents dividing rectangles, SA simulated annealing, GA genetic algorithm, PSO particle swarm optimization and SQP sequential quadratic programming.

For given component sizes, a power split control strategy based on ECMS strategy for a series HEV was developed in [39]; it uses a sequential approach. DP is applied to solve the energy management problem of a parallel HEV with given design parameters [40]. Obviously, the coupling between the component sizes and the controller is ignored in these cases, which find sub-optimal solutions. To consider this dependency, for a parallel HEV, the energy management problem is solved by using DP and the battery, engine and EM sizes are optimized by utilizing CP with an iterative scheme, which is one step forward from the sequential method, resulting in a near-optimal solution [38]. In order to improve solution's optimality, a nested approach is used in [41] for a parallel HEV, where PSO is employed in the outer loop to optimize the component sizes, and the optimal control input for each candidate is selected by adopting DP to minimize the fuel consumption. Furthermore, the authors report that compared to a RB strategy, PSO using optimal control improves the energy efficiency by around $11 \%$ and reduces the cost by around $14 \%$ [41]. For a series HEV, the sizing problem is solved by using PSO at the upper level and the energy management problem is solved by using ECMS at the lower level, by using a nested approach [42]. The effectiveness of the optimization is validated by hardware-in-the-loop experiments, which outperforms a traditional single-upper-level optimization strategy in term of fuel consumption (by around 3.4\%). With a nested coordination scheme, to minimize the TCO of a parallel HEV, the optimal component sizes are found by using SQP in the outer loop, and the optimal power split is solved by utilizing DP in the inner loop [37]. However, the nested approach leads to high computation time. To overcome this limitation, simultaneous optimization of torque split, charging and component sizes is solved via CP [30], which achieves the optimal solution. However, the optimal control problem and the quasi-static models are required to be convex. The advantages and disadvantages of the foregoing optimization structures are summarized in Table 3.

Table 3. Advantages and disadvantages of coordination schemes.

\begin{tabular}{llll}
\hline Strategy & Main Advantages & Main Disadvantages & Application \\
\hline Sequential [39,40] & Easy to implement & No coupling between the plant and controller & Series and parallel HEV \\
Iterative [38] & Computationally efficient & Sub-optimal & Parallel HEV \\
Nested [37,41,42] & Solution optimality & Long computation time & Series and parallel HEV \\
Simultaneous [30] & Strong coupling between the plant and controller & Complex problem formulation & Parallel HEV \\
\hline
\end{tabular}


Notice that all these combined size and control methods are developed for a given vehicle configuration. The topology layer will influence design parameters and control variables. For example, as described in [8], the design and control variables of a parallel HEV are very different from those of a series or a series-parallel topology. Each configuration results in a TCO. Therefore, the generated powertrain architectures $\boldsymbol{T}_{\mathrm{e}}^{f}$ from (1a) should be compared based on TCO.

\subsection{Combined Topology, Size and Control Optimization}

To fully consider the design aspects and to obtain an optimal system, topology optimization should also be taken into consideration. Integrated topology, size and control optimization can be formulated by combining (1a), (2a) and (4a). The goal is to find the best design that has the lowest $T C O_{\mathrm{e}}^{T}$, while satisfying performance requirements, e.g.,

$$
\begin{array}{ll} 
& J_{\mathrm{e}}\left(\boldsymbol{T}_{\mathrm{e}}^{f}, \boldsymbol{s}_{\mathrm{e}}^{T}, \boldsymbol{x}_{\mathrm{e}}(t), \boldsymbol{u}_{\mathrm{e}}^{T}(t)\right)=T C O_{\mathrm{e}}^{T}, \\
\text { s.t. } \quad & \bar{v}\left(\boldsymbol{T}_{\mathrm{e}}^{f}, \boldsymbol{s}_{\mathrm{e}}^{T}, \boldsymbol{x}_{\mathrm{e}}(t), \boldsymbol{u}_{\mathrm{e}}^{T}(t)\right) \geq \bar{v}_{\mathrm{d}}, \\
& t_{\mathrm{a}}\left(\boldsymbol{T}_{\mathrm{e}}^{f}, \boldsymbol{s}_{\mathrm{e}}^{T}, \boldsymbol{x}_{\mathrm{e}}(t), \boldsymbol{u}_{\mathrm{e}}^{T}(t)\right) \leq t_{\mathrm{a}, \mathrm{d}}, \\
& \bar{\alpha}\left(\boldsymbol{T}_{\mathrm{e}}^{f}, \boldsymbol{s}_{\mathrm{e}}^{T}, \boldsymbol{x}_{\mathrm{e}}(t), \boldsymbol{u}_{\mathrm{e}}^{T}(t)\right) \geq \bar{\alpha}_{\mathrm{d}} .
\end{array}
$$

$T C O_{\mathrm{e}}^{T}$ represents the effect of topology on $T C O_{\mathrm{e}}$ in (4a). Specifically, the design parameters $s_{\mathrm{e}}$ and control vector $\boldsymbol{u}_{\mathrm{e}}^{s}$ in (4a) are updated to $\boldsymbol{s}_{\mathrm{e}}^{T}$ and $\boldsymbol{u}_{\mathrm{e}}^{T}$ in (7a), respectively. Performance requirements are in this example the top speed, acceleration time and gradability, which are enforced by $(7 b)-(7 d)$, respectively. Other constraints on control and size optimization are associated with (2a) and (4a).

Recent studies have attempted to investigate the influence of the architecture layer. Note that the four coordination schemes introduced before are also applicable here to solve the combined optimization problem. A layered control strategy is proposed in [43], where a supervisory controller is used to determine the powertrain configuration, including series and parallel types, and an EMS is utilized to determine the power split. Optimal topologies are designed for HEVs with different transmission technologies in [44], which include precoupled, postcoupled and switching topologies, by using DP. A reduction of up to around $8 \%$ in $\mathrm{CO}_{2}$ emission is shown, by finding the optimal fixed topology. For a torque-assist and a full-parallel topology [45] presents a method to identify the best configuration based on minimization of fuel usage and powertrain cost by using DP and PSO with a nested approach. Constraints on top speed and acceleration time are taken into account. However, all those studies only consider a small number of configurations, which may not be optimal. For power-split hybrids with double PGs, [10] generated and evaluated $3.4 \times 10^{9}$ possible configurations. The integrated optimization problem was solved with two methods, namely, nested optimization and iterative optimization. The nested approach based on exhaustive search found the optimal solution, but it was computationally heavy. The iterative method could converge to the optimal design found by the nested one much faster, as shown in Figure 6. It started from an initial design $\left(T_{\mathrm{e}}^{0}, s_{\mathrm{e}}^{0}\right)$, and topology optimization and component sizing were executed alternately. The best design was determined based on the minimum fuel consumption. That study shows that integrated configuration, size and control optimization can improve energy efficiency by around $16.6 \%$, compared to only combined size and control optimization. However, this research did not consider the influence of topology on design and control variables. In addition, only few powertrain parameters were optimized and powertrain cost was not taken into account. 


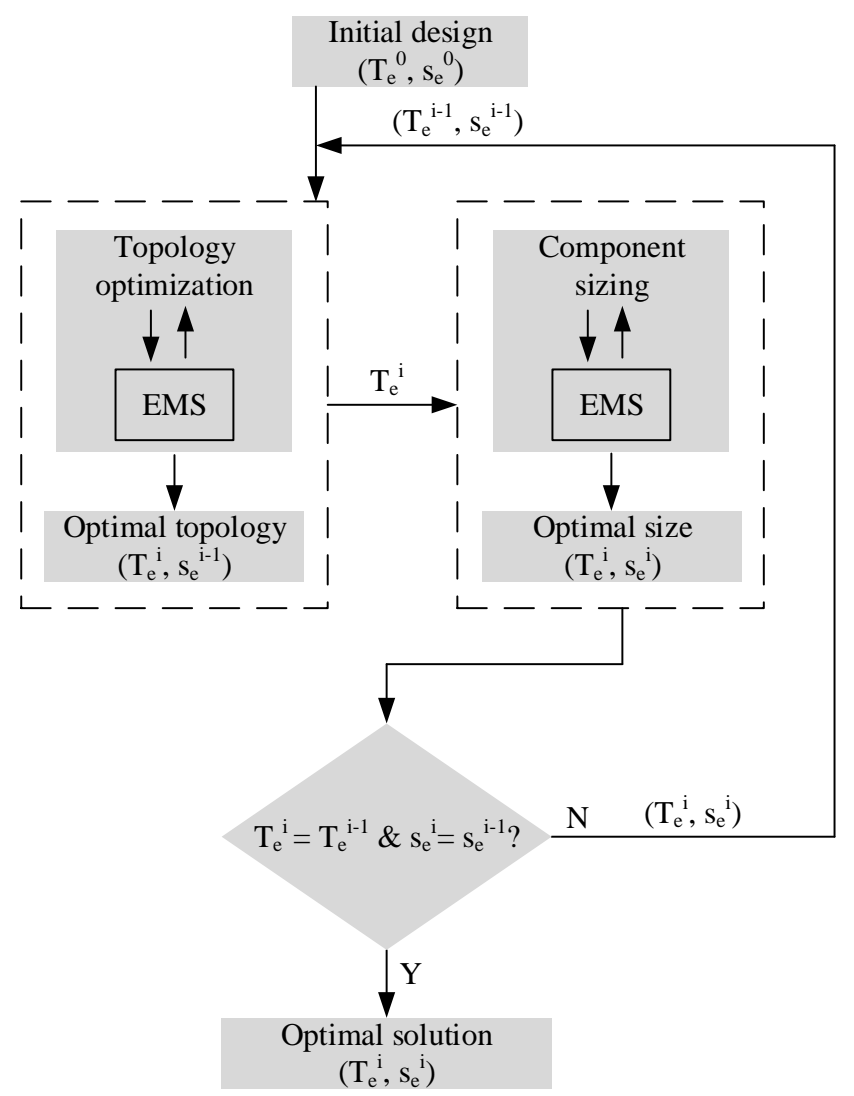

Figure 6. Flowchart of integrated topology, size and control optimization via an iterative approach, where $T_{\mathrm{e}}$ represents the topology and $s_{\mathrm{e}}$ the component size.

Current studies mainly focus on the energy domain. The thermal domain is also important as it influences vehicle energy efficiency and cost, but it is often not considered in optimization problems.

\section{Thermal-Aware Design and Control Optimization}

If a system is only optimized from the thermal viewpoint for a given EMS, for example, finding an optimal thermal management architecture with optimized thermal system size and heating/cooling power flow, it is said to have had thermal-aware design and control optimization.

A TMS may be defined as a system that is capable of maintaining specified component temperatures for efficiency and comfort with minimum power consumption, recovering waste heat energy and exchanging heat between components efficiently. As far as the thermal domain is concerned, combined control, size and configuration optimization is generally not available in the literature. Therefore, these design layers are analyzed separately here.

\subsection{Topology Generation}

Typical temperature levels of electrified powertrain components, also termed heat source components, can be seen in Figure 7. It can be observed that there are three relative temperature levels in an electrified vehicle and three cooling circuits can thus be created. 


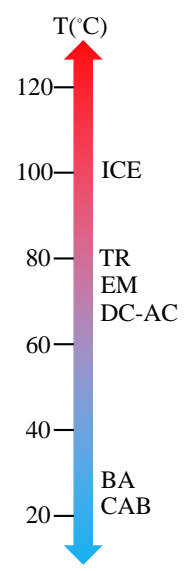

Figure 7. Typical temperature levels of electrified vehicle components, where CAB represents the cabin.

A common thermal management configuration for an electrified powertrain is shown in Figure 8, including both transient and steady-state behaviors. Here, the battery is cooled with an air conditioning (AC) system onboard [2]. The transmission is cooled with the electric drive circuit [46]. For example, the engine is not only a power source but also a heat source. When $\theta_{\mathrm{e}}<\bar{\theta}_{\mathrm{e}}$, indicating the transient behavior, the engine heats up itself and the radiator as the heat sink is bypassed. When $\theta_{\mathrm{e}} \geq \bar{\theta}_{\mathrm{e}}$, representing the steady-state phase, the fluid circulated by the pump as the fluid delivery device flows through the radiator to remove heat from the engine. This process is controlled by the thermostat as the control device. The same analysis can be applied to other powertrain components.

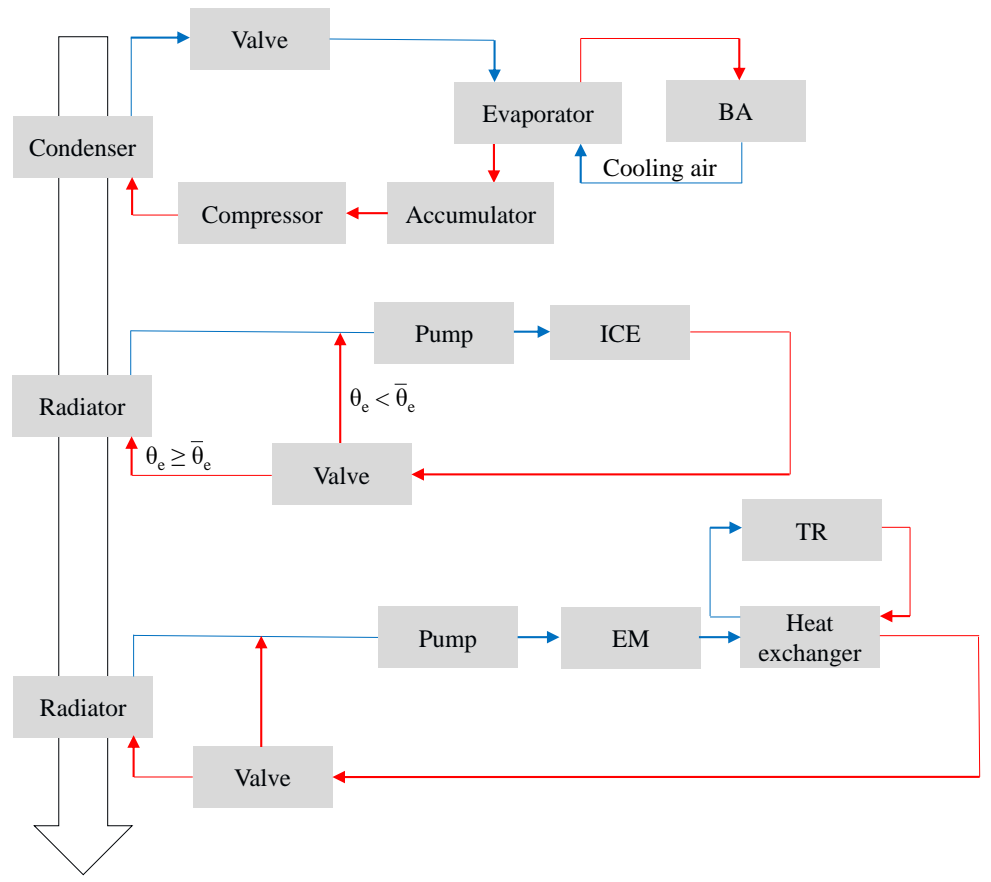

Figure 8. A common thermal management configuration for a series hybrid electric vehicle, where the blue line represents the cold cooling medium, the red line the hot cooling medium, which can be gaseous and liquid (water and oil), $\theta_{\mathrm{e}}$ the engine temperature and $\bar{\theta}_{\mathrm{e}}$ the desired engine temperature. 
From the thermal perspective, automatic topology generation is not available in the literature. If automatic generation of thermal management architectures is considered, similarly to the energy domain in Section 2.1, feasible thermal management topologies can be found by

$$
\begin{aligned}
\text { Generate } & \boldsymbol{T}_{\mathrm{t}}^{f} \subseteq \boldsymbol{T}_{\mathrm{t}}^{p}, \\
\text { s.t. } & g_{\mathrm{t}}\left(\boldsymbol{T}_{\mathrm{t}}^{f}\right) \leq 0,
\end{aligned}
$$

where subscript $t$ represents the thermal domain, $\boldsymbol{T}_{\mathrm{t}}^{p}$ the possible thermal management architectures and $T_{\mathrm{t}}^{f}$ the feasible thermal management configurations. Equation (8b) represents constraints; for example, each cooling circuit should have at least a heat source component, a heat sink and a fluid delivery device, to filter out infeasible topologies. The generated feasible architectures have yet to be evaluated based on TCO and packaging constraints, by combining with control and size layers.

\subsection{Control Optimization}

In this regard, previous studies mostly concentrated on the control layer for a given thermal management configuration $\boldsymbol{T}_{\mathrm{t}}^{f}$ generated from (8a) and fixed thermal system parameters (e.g., heating/cooling capacity in $\mathrm{kW}$ ) denoted by $\boldsymbol{s}_{\mathrm{t}}$. Different techniques can be used to model thermal systems based on number of dimensions, e.g., from black box and 0D models to 3D models [1,47]. Black box models are fast but cannot capture system dynamics. 3D computational fluid dynamics are useful for predicting high frequency dynamics and providing detailed design considerations. However, the computation time is high (e.g., 2000 times longer than the actual process). The 0D modeling technique (e.g., lumped capacitance analysis method), which strikes a balance between computation time (e.g., real-time) and model fidelity (e.g., capturing low frequency dynamics with sufficient accuracy), is widely used for controller design. The main goals of the controller (TMS) are to improve temperature tracking with respect to a prescribed threshold of the component and to reduce heating/cooling power consumption $J_{t}$, i.e.,

$$
\begin{array}{ll} 
& J_{\mathrm{t}}\left(\boldsymbol{x}_{\mathrm{t}}(t), \boldsymbol{u}_{\mathrm{t}}(t), t \mid\left(\boldsymbol{T}_{\mathrm{t}}^{f}, \boldsymbol{s}_{\mathrm{t}}\right)\right)=\int_{t_{0}}^{t_{\mathrm{f}}}\left[\left(\boldsymbol{x}_{\mathrm{t}}-\boldsymbol{x}_{\mathrm{t}, \mathrm{d}}\right)^{T} R_{x}\left(x_{\mathrm{t}}-\boldsymbol{x}_{\mathrm{t}, \mathrm{d}}\right)+\right. \\
& \left.\left(\boldsymbol{u}_{\mathrm{t}}-\boldsymbol{u}_{\mathrm{t}, \mathrm{d}}\right)^{T} R_{\boldsymbol{u}}\left(\boldsymbol{u}_{\mathrm{t}}-\boldsymbol{u}_{\mathrm{t}, \mathrm{d}}\right)\right] \mathrm{d} t \\
\text { s.t. } & \dot{x}_{\mathrm{t}}(t)=\boldsymbol{f}\left(\boldsymbol{x}_{\mathrm{t}}(t), \boldsymbol{u}_{\mathrm{t}}(t), t\right) \\
& \boldsymbol{x}_{\mathrm{t}} \in\left[\underline{\boldsymbol{x}}_{\mathrm{t}}, \overline{\boldsymbol{x}}_{\mathrm{t}}\right] \\
& \boldsymbol{u}_{\mathrm{t}} \in\left[\underline{\boldsymbol{u}}_{\mathrm{t}}, \overline{\boldsymbol{u}}_{\mathrm{t}}\right]
\end{array}
$$

where $x_{\mathrm{t}}$ represents the vector of thermal state variables. Equation $(9 \mathrm{~b})$ represents the thermodynamics of the system, e.g., the EM temperature $\theta_{\mathrm{m}}$, which depends on how the EM is used from the EMS $\left(\boldsymbol{u}_{\mathrm{e}}\right)$ (see (2a)), resulting in different power losses $P_{\mathrm{m}, \text { loss }}$ (heat generation) and yielding

$$
\dot{\theta}_{\mathrm{m}}=\frac{P_{\mathrm{m}, \mathrm{loss}}}{C_{\mathrm{m}}}
$$

where $C_{\mathrm{m}}$ is the EM heat capacity. However, the EM temperature is constrained by (9c). Therefore, cooling power is required to keep the EM temperature below its thermal limit. $\boldsymbol{u}_{\mathrm{t}}$ denotes the control variables; for example, the cabin heating power $P_{\mathrm{c}}$,

$$
P_{\mathrm{c}}(t) \in\left[\underline{P}_{\mathrm{c}}, \bar{P}_{\mathrm{c}}\right]
$$

$x_{\mathrm{t}, \mathrm{d}}$ and $u_{\mathrm{t}, \mathrm{d}}$ are the references of the state vector and control vector, respectively. $R_{x}$ and $R_{u}$ are the weighting matrices. 
This control problem can be tackled by two major groups of strategies: $\mathrm{RB}$ and $\mathrm{OB}$, as shown in Figure 9. RB approaches utilize a set of rules to compute the control signals on the basis of predefined thresholds. These thresholds are often determined based on expert knowledge. An on/off control method is utilized in [48] for battery cooling. The cooling system is triggered on with maximum speed, when the battery temperature is greater than the prescribed upper threshold. The cooling system is switched off when the battery temperature is lower than the predefined lower limit. Moreover, the on/off control strategy is typically related to mechanical actuators, such as mechanical fans and pumps that are coupled with the engine through clutches, which have only two states, open and closed. Due to engine speed-dependent actuation, this kind of system often proves more than necessary, leading to parasitic losses and excess energy usage. For the EM TMS of a series HEV, a proportional-integral controller is used to improve the tracking performance based on the error between the hot spot temperature and the target temperature [49]. The proportional and integral gains need to be tuned and the solution optimality cannot be guaranteed. RB methods are easy to understand and implement. However, they generally require tuning and yield non-optimal solutions. To reduce energy consumption, of particular importance is adopting electrified actuators, e.g., electronic thermostats, electric fans, electric water pumps and electric compressors, instead of their mechanical counterparts. Continuous adjustment of thermal actuators is now possible, for example, with motors. Costs of electrified actuators are higher, which depend on their sizes. Note that the price difference is decreasing. In this context, OB controllers can be used to provide heating/cooling on demand, depending on driving conditions. DP is applied to minimize the power consumption of the battery cooling system of a series HEV [50]. An electric radiator fan matrix of an engine cooling system is controlled to minimize the cooling power consumption by using mixed integer nonlinear programming in [51]. Energy savings of up to $67 \%$ can be achieved. This method has the advantage of solving nonlinear problems with continuous and integer variables. However, the optimization result depends on model fidelity and assumptions, and this strategy is not real-time implementable. To improve the tracking performance and reduce the power consumption of the electrical components' cooling circuit of a parallel HEV, a real-time nonlinear MPC was developed [52]; it reduces the electrical consumption by up to $8 \%$, compared to a finite-state machine method. However, this strategy is complex, which requires model simplification, and the performance depends on the drive cycle and cost function formulation in the presence of multiple objectives. The advantages and disadvantages of the foregoing thermal management strategies are summarized in Table 4.

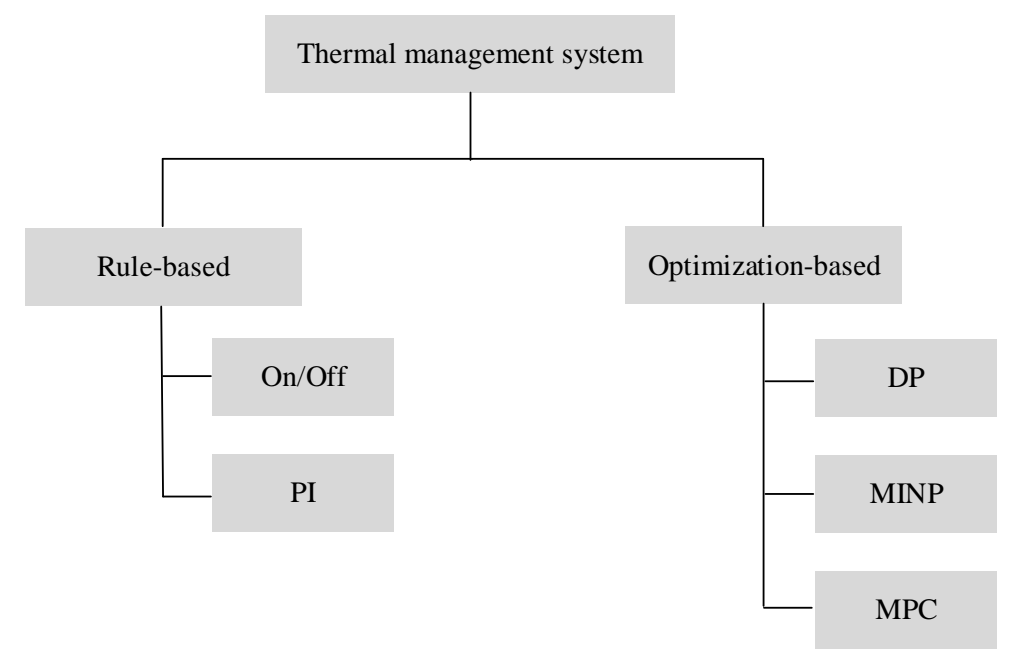

Figure 9. Thermal management strategies, where PI represents proportional-integral and MINP mixed integer nonlinear programming. 
Table 4. Advantages and disadvantages of thermal management strategies.

\begin{tabular}{llll}
\hline Strategy & Main Advantages & Main Disadvantages & Application \\
\hline On/Off [48] & Easy to implement & Unnecessary power consumption & Battery cooling system \\
PI [49] & Improved tracking performance & Tuning of parameters & Electric machine cooling system \\
DP [50] & Global optimal & Curse of dimensionality & Battery cooling system \\
MINP [51] & Handling continuous and integer variables & Not implementable & Engine cooling system \\
MPC [52] & Real-time implementation & Model fidelity & Electrical components of a parallel HEV \\
\hline
\end{tabular}

It should be noted that the control action of the TMS is not checked by the EMS, which may not be optimal. The TMS has yet to be integrated into the EMS, where the control signal of the TMS is generated from the EMS, considering overall energy consumption from both energy and thermal aspects.

Additionally, all these thermal management strategies are developed for a given thermal system size. However, the thermal system size influences the control strategy and vice versa. For example, a large radiator would reduce the need of providing more cooling power. The control algorithm helps optimize the thermal system size [53]. Furthermore, the thermal system size affects the system cost. From the thermal perspective, the control layer has yet to be integrated with the size layer.

\subsection{Size Optimization}

All powertrains have tight packaging constraints. It is desirable to reduce cooling system size, resulting in reduced volume, weight, air drag, parasitic losses and cost, while meeting cooling requirements. The main sizing methods can be categorized into $\mathrm{RB}$ and $\mathrm{OB}$ strategies.

As described in [54], the cooling capacity of a radiator is proportional to the temperature difference between the component coolant temperature and the cooling air temperature. Moreover, reference [54] shows that for the engine cooling system of a minivan, increasing the temperature difference by around $20{ }^{\circ} \mathrm{C}$ can reduce the radiator size by around $30 \%$. This can be achieved by increasing the component coolant temperature through technological advancements [55] in which powertrain components can work at elevated temperatures that are still lower than their allowable limits to avoid failure. For the engine cooling system of a class 3 pickup truck, reference [56] demonstrated that the pump power can be reduced significantly by around $87 \%$ and the radiator can be downsized by around $27 \%$ under a grade load condition on the FTP 74 driving cycle. This was realized by upgrading the mechanical water pump to an electric one. However, solution optimality in terms of radiator size could not be guaranteed in these studies, which motivated the development of OB strategies.

For a series hybrid heavy duty vehicle under a grade load condition, reference [57] took a reference to a similar class of conventional vehicle to obtain the initial cooling system parameters. The optimal pump and radiator sizes were found by using SQP to minimize power consumption, subject to temperature and packaging constraints. Taking into account cooling power consumption and heat removal capability, a search-based optimization algorithm was implemented in [58] to minimize the heat exchanger size of the engine cooling system of a heavy duty military truck, subject to a power constraint. However, the size layer and the control layer have yet to be coupled to obtain better thermal system designs.

For a fixed thermal management topology, if the control and size loops are integrated, the optimal control problem may be formulated as follows:

$$
\begin{array}{ll} 
& J_{\mathrm{t}}\left(\boldsymbol{s}_{\mathrm{t}}, \boldsymbol{x}_{\mathrm{t}}(t), \boldsymbol{u}_{\mathrm{t}}^{s}(t), t \mid \boldsymbol{T}_{\mathrm{t}}^{f}\right)=T C O_{\mathrm{t}}=\int_{t_{0}}^{t_{\mathrm{f}}}\left(\gamma P_{\mathrm{t}}\left(s_{\mathrm{t}}, \boldsymbol{x}_{\mathrm{t}}(t), \boldsymbol{u}_{\mathrm{t}}^{s}(t), t\right)\right) \mathrm{d} t+C_{\mathrm{t}}\left(\boldsymbol{s}_{\mathrm{t}}\right), \\
\text { s.t. } & \dot{x}_{\mathrm{t}}(t)=f\left(s_{\mathrm{t}}, \boldsymbol{x}_{\mathrm{t}}(t), \boldsymbol{u}_{\mathrm{t}}^{s}(t), t\right), \\
& \boldsymbol{x}_{\mathrm{t}} \in\left[\underline{\boldsymbol{x}}_{\mathrm{t}}, \overline{\boldsymbol{x}}_{\mathrm{t}}\right] \\
& \boldsymbol{u}_{\mathrm{t}}^{s} \in\left[\underline{u}_{\mathrm{t}}^{s}, \overline{\boldsymbol{u}}_{\mathrm{t}}^{s}\right] \\
& \boldsymbol{s}_{\mathrm{t}} \in\left[\underline{s}_{\mathrm{t}}, \overline{\boldsymbol{s}}_{\mathrm{t}}\right],
\end{array}
$$


where $T C O_{\mathrm{t}}$ denotes the energy consumption and cost of the thermal system. The thermal power $P_{\mathrm{t}}$ is converted to cost using $\gamma$. $s_{\mathrm{t}}$ denotes the thermal design parameters, e.g., the pump scaling factor, and $C_{t}$ the thermal system cost. As of the effect of $\boldsymbol{s}_{\mathrm{t}}$, the control variable $\boldsymbol{u}_{\mathrm{t}}$ in (9a) was updated to $\boldsymbol{u}_{\mathrm{t}}^{s}$ in (12a), which reveals the strong coupling between them.

Note that the component sizing strategies (Figure 5) from the energy domain can theoretically also be employed here. Hence, the combination of the size layer from Figure 5 and the control layer from Figure 9 yield different solution methods to (12a), which are connected with the four coordination schemes introduced in Figure 2. Furthermore, the size of the powertrain component influences its cooling system size. For example, a downsized and more efficient engine would imply a compact and smaller cooling system; i.e., $s_{\mathrm{t}} \propto s_{\mathrm{e}}$. It indicates that the thermal system size is proportional to the powertrain component size. Moreover, similarly to (6), the thermal system size affects the control decision of the TMS. Additionally, topology optimization needs to be considered, as thermal management configurations are important for efficiency, comfort, cost and reliability.

\subsection{Topology Optimization}

In general, designs of thermal management architectures for electrified vehicles are less available, compared to designs of powertrain configurations. Compared with conventional vehicles, thermal management of power electronics and EM adds a new challenge to electrified ones. Normally, power electronics (inverter) and EM are combined together with a dedicated water or oil cooling circuit because the coolant temperature is in a similar range, as illustrated in Figure 7. In order to reduce size, weight and cost, two ways of integration of cooling circuits for a parallel HEV were proposed in [46]. The first method is to incorporate the power electronics and EM cooling loop into the engine cooling circuit and the second approach is to combine it with the AC circuit. The criteria combine systems having similar temperature levels and exhibiting misalignment of peak heat loads after integration. For the first strategy, even though it seems possible to combine them with respect to misalignment of peak heat loads, the issue remains the different temperature specifications of the engine and power electronics and EM as mentioned before. It is reported that future technologies may be able to increase the temperature of electronic modules [55]. However, currently it is still an obstacle. Regarding the second approach, it appears that this integration meets the requirements stated above, for instance, with a low temperature liquid coolant, but a thorough analysis is required to verify such concepts.

Comprehensive thermal modeling and architecture design guidelines are given in [11] for a heavy-duty series HEV, where two induction motors are used to drive the wheels. Two main design guidelines derived can be summarized as follows. Heat sources with different temperature specifications should not share the same cooling loop. Moreover, powertrain components working in different operation groups should not share the same cooling circuit. Based on these guidelines and simulation results in terms of power consumption of the cooling system, the authors proposed the following topology [59], as demonstrated in Figure 10. Obviously, this system is modular because almost all the components have their own cooling loops. However, considering of cost, weight and size, this configuration is hardly appealing. The authors report that in this case, parasitic losses can be reduced significantly, resulting in fuel savings of up to around $6.1 \%$, because of the separate loops compared with combined circuits. In combined loops, powertrain components are cooled in a single circuit, where the coolant temperature is limited by the component that has the lowest temperature specification, resulting in over-cooled components and unnecessary power consumption. However, one of the reasons may be that not all the components in this system are electronically controlled, leading to this conclusion. Here, the simulation results are dependent on the simulation conditions, assumptions and vehicle type. 

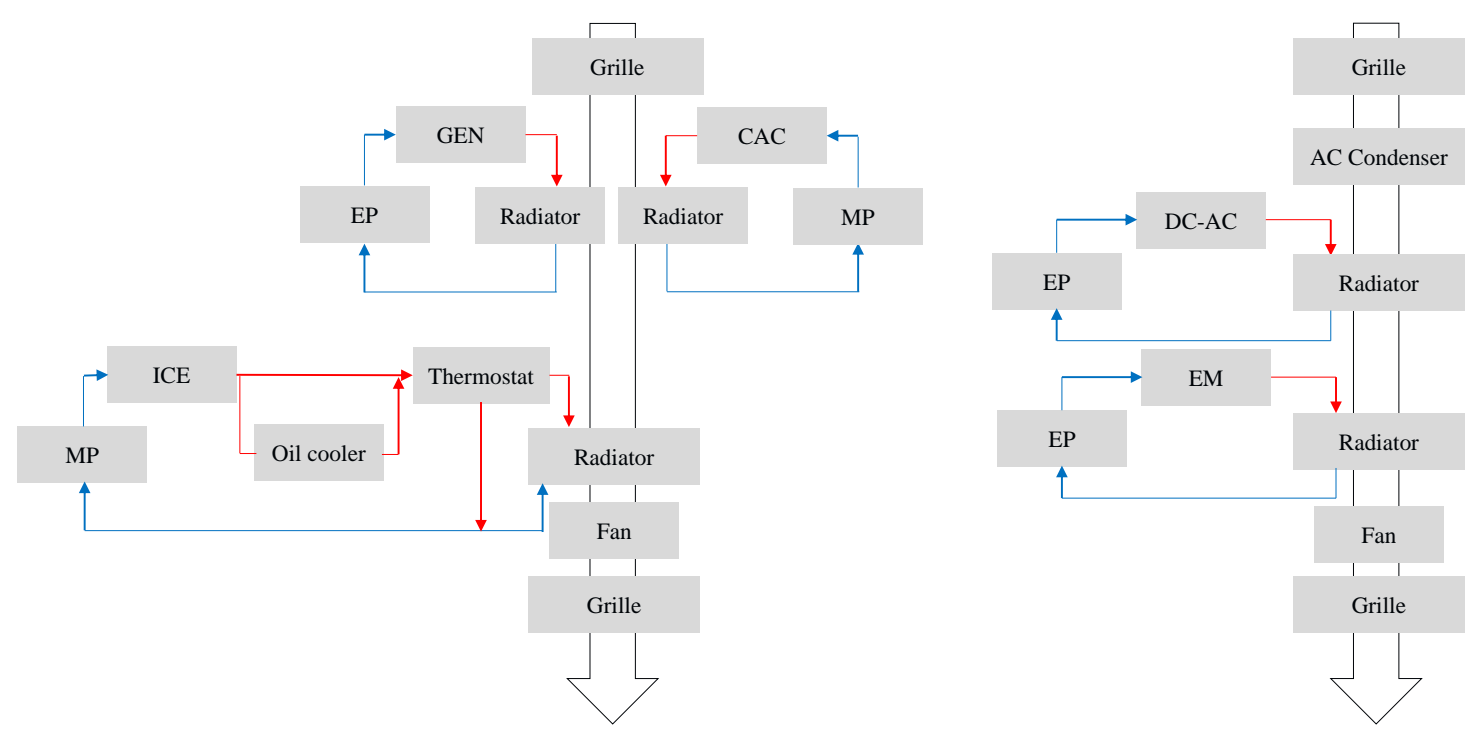

Figure 10. Thermal management architecture for a series hybrid electric vehicle, where MP represents the mechanical pump, EP the electric pump and CAC the charge air cooler.

Overall, current thermal management topologies for electrified vehicles are designed based on expert knowledge, and the identified architecture is likely sub-optimal because of limited choices. Moreover, in order to obtain an optimal thermal management configuration, topology optimization has to be coupled with the size and control layers. If these layers are integrated, e.g., by combining (8a), (9a) and (12a), for simplicity, the optimization problem may be described as

$$
\begin{array}{ll} 
& J_{\mathrm{t}}\left(\boldsymbol{T}_{\mathrm{t}}^{f}, \boldsymbol{s}_{\mathrm{t}}^{T}, \boldsymbol{x}_{\mathrm{t}}(t), \boldsymbol{u}_{\mathrm{t}}^{T}(t)\right)=T C O_{\mathrm{t}}^{T}, \\
\text { s.t. } & \theta_{\mathrm{i}}\left(\boldsymbol{T}_{\mathrm{t}}^{f}, \boldsymbol{s}_{\mathrm{t}}^{T}, \boldsymbol{x}_{\mathrm{t}}(t), \boldsymbol{u}_{\mathrm{t}}^{T}(t)\right) \leq \theta_{\mathrm{i}, \mathrm{d}}, \\
& V\left(\boldsymbol{T}_{\mathrm{t}}^{f}, \boldsymbol{s}_{\mathrm{t}}^{T}, \boldsymbol{x}_{\mathrm{t}}(t), \boldsymbol{u}_{\mathrm{t}}^{T}(t)\right) \leq V_{0},
\end{array}
$$

where $T C O_{t}^{T}$ represents the influence of topology on $T C O_{t}$ in (12a). To be more specific, the design parameters $\boldsymbol{s}_{\mathrm{t}}$ and control vector $\boldsymbol{u}_{\mathrm{t}}^{s}$ in (12a) are changed to $\boldsymbol{s}_{\mathrm{t}}^{T}$ and $\boldsymbol{u}_{\mathrm{t}}^{T}$ in (13a), respectively. Equation (13b) ensures that the component temperature is always maintained below its thermal limit and $(13 \mathrm{c})$ means that the thermal system should respect the packaging constraint. Other constraints are related to (9a) and (12a). This optimization problem can be solved in a similar fashion as (7a).

Additionally, given the strong coupling between energy and thermal domains, a suitable thermal management topology should be determined in combination with energy-aware design and control optimization.

\section{Energy and Thermal-Aware Design and Control Optimization}

Taking into account design and control aspects, if a system is optimized from both energy and thermal perspectives, it is said to have energy and thermal-aware design and control optimization.

\subsection{Topology Generation}

Choosing a suitable powertrain and thermal management configuration is vital, since it affects vehicle energy efficiency, cost, performance, comfort and reliability. From both energy and thermal viewpoints, automatic topology generation is not available in the literature. If automatic generation of 
powertrain and thermal management architectures is taken into consideration, feasible powertrain and thermal management configurations can be identified by combining (1a) and (8a), given by

$$
\begin{aligned}
\text { Generate } & \boldsymbol{T}_{\mathrm{e}, \mathrm{t}}^{f} \subseteq T_{\mathrm{e}, \mathrm{t}}^{p} \\
\text { s.t. } & g_{\mathrm{e}, \mathrm{t}}\left(\boldsymbol{T}_{\mathrm{e}, \mathrm{t}}^{f}\right) \leq 0,
\end{aligned}
$$

where $\boldsymbol{T}_{\mathrm{e}, \mathrm{t}}^{f}$ represents the feasible powertrain and thermal management topologies and $\boldsymbol{T}_{\mathrm{e}, \mathrm{t}}^{p}$ the possible powertrain and thermal management configurations. Equation (14b) includes the constraints from (1a) and (8a). The generated feasible architectures have yet to be compared based on TCO, by integrating with control and size layers.

\subsection{Control Optimization}

Earlier works mainly focused on the control layer for a given topology $\boldsymbol{T}_{\mathrm{e}, \mathrm{t}}^{f}$ generated by (14a) and fixed powertrain and thermal parameters represented by $s_{\mathrm{e}}$ and $s_{\mathrm{t}}$. The aim of an integrated energy and thermal controller is to optimally decide on the power flow of the electrified powertrain while considering the energy and thermal aspects to minimize the overall energy consumption and satisfying the driver demand and heating/cooling requirements. By combining (2a) and (9a), this control problem can be expressed as

$$
\begin{aligned}
& J_{\mathrm{e}, \mathrm{t}}\left(\boldsymbol{x}_{\mathrm{e}}(t), \boldsymbol{x}_{\mathrm{t}}(t), \boldsymbol{u}_{\mathrm{e}}(t), \boldsymbol{u}_{\mathrm{t}}(t), t \mid\left(\boldsymbol{T}_{\mathrm{e}, t}^{f}, \boldsymbol{s}_{\mathrm{e}}, \boldsymbol{s}_{\mathrm{t}}\right)\right)=\int_{t_{0}}^{t_{\mathrm{f}}}\left[w_{\mathrm{p}}\left(P_{\mathrm{e}}\left(\boldsymbol{x}_{\mathrm{e}}(t), \boldsymbol{x}_{\mathrm{t}}(t), \boldsymbol{u}_{\mathrm{e}}(t), \boldsymbol{u}_{\mathrm{t}}(t), t\right)\right)+\right. \\
& \left.w_{\mathrm{t}}\left(P_{\mathrm{t}}\left(x_{\mathrm{e}}(t), x_{\mathrm{t}}(t), \boldsymbol{u}_{\mathrm{e}}(t), \boldsymbol{u}_{\mathrm{t}}(t), t\right)\right)\right] \mathrm{d} t, \\
& \text { s.t. } \quad \dot{x}_{\mathrm{e}}(t)=f\left(x_{\mathrm{e}}(t), x_{\mathrm{t}}(t), u_{\mathrm{e}}(t), u_{\mathrm{t}}(t), t\right) \text {, } \\
& \dot{x}_{\mathrm{t}}(t)=f\left(x_{\mathrm{e}}(t), x_{\mathrm{t}}(t), u_{\mathrm{e}}(t), u_{\mathrm{t}}(t), t\right) \text {, } \\
& h_{\mathrm{e}, \mathrm{t}}\left(x_{\mathrm{e}}(t), x_{\mathrm{t}}(t), u_{\mathrm{e}}(t), u_{\mathrm{t}}(t), t\right)=0 \text {, } \\
& g_{\mathrm{e}, \mathrm{t}}\left(x_{\mathrm{e}}(t), x_{\mathrm{t}}(t), u_{\mathrm{e}}(t), u_{\mathrm{t}}(t), t\right) \leq 0,
\end{aligned}
$$

where $w_{\mathrm{p}}$ and $w_{\mathrm{t}}$ are the weights. The energy domain and the thermal domain are coupled, as can be seen in the constraints.

The associated algorithm to solve (15a) is referred to as the energy and thermal management system. Recall that there are two categories for both EMSs and TMSs: RB and OB algorithms. Hence, the combination of the EMS from Figure 4 represented by $\{R B, O B\}$ and the TMS from Figure 9 represented by $\{R B, O B\}$ yield different solution methods represented by $\{R B, O B\} \times\{R B, O B\}$ to (15a). Consequently, energy and thermal management systems can be divided into two principle groups, separate energy and thermal management systems (SETMSs) and combined energy and thermal management systems (CETMSs), as shown in Table 5; examples can be found in the literature [60]. The SETMS is denoted by EMS + TMS, while the CETMS is denoted by (EMS,TMS). The key difference is that the control variables are determined simultaneously at the supervisory level in a CETMS, considering whether the control decision of the TMS is energy beneficial. The TMS receives the control signal from the EMS, which can be seen in Figure 11. In a SETMS, however, there are explicitly two layers, and the EMS and the TMS are treated independently. 
Table 5. Energy and thermal management strategies.

\begin{tabular}{lllll}
\hline Control Strategy & Composition & Optimality & Causality & Application \\
\hline \multirow{4}{*}{ SETMS } & PF + On/Off & Sub-optimal & Causal & Heavy-duty series HEV powertrain [11] \\
& TC + MPC & Sub-optimal & Causal & Battery pack of a series HEV [61] \\
& ECMS + On/Off & Sub-optimal & Causal & Battery of a hybrid electric truck [62] \\
& OB + MPC & Sub-optimal & Causal & HEV powertrain [2] \\
\hline \multirow{4}{*}{ CETMS } & (RB, RB) & Sub-optimal & Causal & Engine and electrical power equipment of an HEV [63] \\
& (RB, OB) & Sub-optimal & Causal & Engine and electrical power equipment of an HEV [63] \\
& (DO, On/Off) & Close-to-optimal & Acausal & Climate control system, refrigerated semitrailer, and air supply system [64] \\
& (DP, MPC) & Optimal & Acausal & Battery pack of a series HEV [50] \\
\hline
\end{tabular}

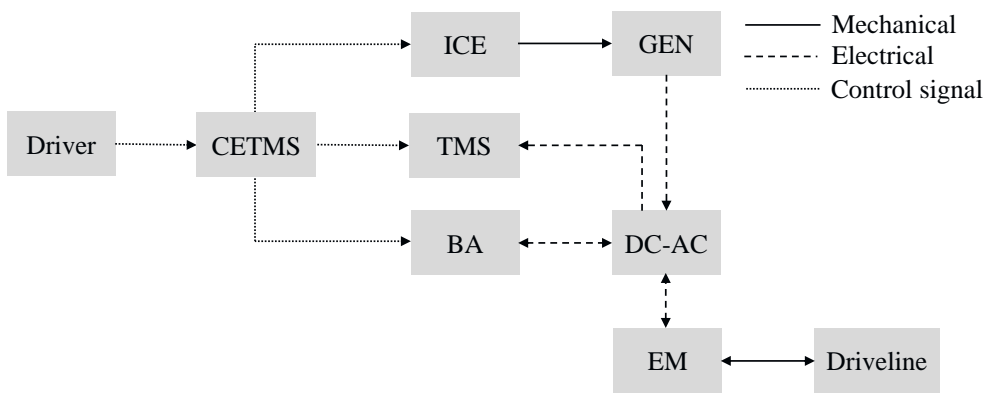

Figure 11. Combined energy and thermal management.

Previous research mostly focused on SETMSs. For a heavy-duty series HEV powertrain, a PF control strategy was developed in [11] based on heuristics to decide on the operation of a power generation unit to meet the power request from the driver. Powertrain components generate heat accordingly. A low-level on/off controller is utilized to remove the heat to keep the components' temperatures below their prescribed thermal limits. These controllers are easy to implement and can be used in real-time control. However, they cannot provide an economic solution in terms of energy consumption, because both control strategies are RB. An improved version is presented in [61]; even though the EMS is similar, a TC, the TMS was developed based on MPC, which reduces cooling power consumption. A clear drawback of this study is that the EMS is a RB method, which generates a non-optimal set-point of the power source and has a negative impact on the MPC result. To overcome this limitation, for an HEV powertrain, both OB algorithms were implemented for high-level energy management and low-level thermal management in [2] to improve energy efficiency. However, the EMS did not verify whether the control action of the TMS is energy beneficial, resulting in a sub-optimal solution. This disadvantage of SETMSs motivated the development of CETMSs, which started to appear recently and were proven to be superior to their separate counterparts [62].

In this respect, the EMS designed based on rules still cannot yield an optimal solution, regardless of the TMS used [63]. To overcome this issue, an online energy and battery TMS was presented in [65] to tackle multiple states with energy dynamics and thermodynamics. The battery pack can be cooled down with a radiator or chilled down with a chiller in association with an AC system, which maintains the battery temperature within its optimal range. The switch between the cooling mode and the chilling mode is decided by physics. The AC compressor can only be turned on or off, as it is linked to the engine with a clutch. The propulsion and cooling requirements are eventually met by the engine. The main objective is to minimize the fuel consumption, while keeping the battery temperature within its optimal range, by finding the optimal control inputs. This problem is solved with ECMS (Figure 4). The optimal solution is found using necessary conditions and the initial values of the co-states are calculated offline. Proportional controllers are employed to update co-states in real-time. Fuel savings of around $1.8 \%$ were reported, compared to its separate counterpart, where the EMS makes decisions without considering the battery cooling power consumption, i.e., ECMS + on/off [65]. Note that the solution can be sensitive to the initial values of the co-states [27]. It is also sensitive to the physics-based mode selection. Moreover, even though in this study only battery thermal management was taken into account, this method can be extended to consider other powertrain components. 
However, as the number of states increases, many parameters need to be tuned and the optimal solution cannot be obtained, which necessitates the development of offline optimal control strategies.

In order to tackle these problems, a scalable distributed optimization approach is proposed in [64], concentrating on convex approximation of auxiliaries. The auxiliaries consist of an air supply system, a refrigerated semitrailer and a climate control system, which can only be turned on or off, as they are connected to the engine with clutches. The complete problem can be seen as an energy network. Each auxiliary is a subsystem of the energy network, comprising energy storage systems, for example, the battery, and converters, for instance, the EM. The aim is to minimize the fuel consumption of the whole system, which is equivalent to minimizing the energy losses of the subsystems. The subsystems are connected to meet the power demand. To preserve convexity, quadratic equality constraints that describe the input and output power of the converter are relaxed to inequality constraints. It should be noted that the equality holds at the optimum [30]. In the presence of propulsion requirements, where power is aggregated in the energy network, the problem cannot be separated and solved easily. The original problem is then decomposed into several smaller optimization problems via dual decomposition, which augments the cost function with the power demand. Owing to the one-on-one mapping between the subsystem and the Lagrange dual function, the subsystems can be solved individually and efficiently, by utilizing Lagrangian method and alternating direction method of multipliers. Compared with its separate counterpart, where the EMS and the TMS are treated independently, fuel savings of around $1.08 \%$ were reported [64]. The presented method can be extended to include more thermal systems. However, in this study, the TMS was limited to on/off control, leading to a large number of switches and excess power consumption, which needs to be upgraded to optimal controllers.

To address this issue, reference [50] presents an integrated DP and MPC approach. The system architecture is similar to Figure 11, where the CETMS represented by DP consideres both propulsion and battery cooling requirements. The TMS represented by MPC receives the control signal from DP to regulate an AC system so as to maintain the battery temperature within its optimal range. Specifically, the cooling air circulated by an air pump, removes heat from the battery. The compressor that is attached to the EM provides the desired coolant flow rate continuously. In view of high computation time of DP, the battery cooling system is simplified as a static map, where the compressor power of the $\mathrm{AC}$ system is described as a function of heat rejection and cooling air temperature. The propulsion power and the cooling power are ultimately met by the battery power and engine-generator power. Overall, the system has two state variables, the state of charge of the battery and cooling air temperature, and two control variables, the engine-generator power and compressor power. Discretization of these variables is required, which entails a trade-off between accuracy and computation time [9]. The objective is to evaluate system dynamics and find optimal control variables at each time instance to minimize the fuel consumption in charge sustaining mode. Compared to a SETMS as the baseline, where the energy management and the thermal management are not integrated, up to roughly $5 \%$ in fuel savings was achieved [50]. Note that, however, the result can be sensitive to the discretization of those state and control variables. In addition, simplified models are not representative in reality. Moreover, as the number of states grows, it can be expected that the computation time increases exponentially, which may not be tractable.

However, the foregoing studies only consider control optimization and the plant has yet to be incorporated to obtain an optimal system. 


\section{Observations and Future Trends}

\subsection{Controller Design}

From EMS point of view, OB algorithms (Figure 4) are gaining popularity, such as using DP as an offline strategy to obtain a global optimal solution to benchmark online controllers. Since DP is computationally heavy, to shorten the computation time and achieve the same accuracy, $\mathrm{CP}$ is a promising alternative. Even though the online counterparts of the offline OB methods facilitate real-time implementation, to simplify the problem, rules can be extracted from offline OB algorithms to form control strategies. An example is RB-DP [43], which strikes a balance between optimality, computation time and complexity. Moreover, taking into account discrete variables, for example, engine on/of and gear shift [66], which results in a mixed-integer optimization problem, necessitates the development of integrated algorithms [67] and hybrid optimal control techniques [68]. In [67], the engine on/off and gear shift are determined by DP in the outer loop, and the continuous variable, power split, is solved by using CP in the inner loop. Apart from energy consumption (fuel and electricity), the objective function to be minimized is also expected to consider more factors to find the trade-off, such as emissions for eco-driving [69], battery aging for cost reduction [70] and drivability for comfort [71]. Additionally, to further increase powertrain efficiency, it is essential to include the thermal domain.

From TMS perspective, since conventional mechanical actuators with the on/off control method fail to provide an economic solution, the current trend is to upgrade them to their electrified counterparts, enabling heating/cooling on demand with OB algorithms [72]. Compared with a traditional control method, the overall power consumption of the cooling system with advanced electromechanical actuators and control strategies can be reduced by around 45\% [73].

Regarding energy and thermal management systems, as CETMSs achieve better performance than their separate counterparts, they will get more and more attention. As is made evident by Table 5, there are eight ways of integrating energy and thermal management systems, but limited comparisons can be found in the literature. To identify energy savings in different scenarios, it is important to conduct more comparisons. Furthermore, in CETMSs, there is a trade-off between optimality, complexity, causality and computation time. Such integrated systems can also communicate with other electronic control units onboard and provide guidelines for drivers via human machine interface to maximize efficiency.

Currently, however, only the control layer has been taken into consideration for energy and thermal management systems. To obtain an optimal system and reveal the real coupling between the energy and thermal domains, it is imperative to incorporate the design layer.

\subsection{Waste Heat Recovery}

To gain insights into areas where most of the powertrain efficiency improvements could be attained, a simulation was conducted to analyze the energy balance of an HEV with cabin heating in charge sustaining mode, as demonstrated in Figure 12 [74]. It can be seen that a large portion of the fuel energy is dissipated as exhaust gas. Recovering a part of that energy would promote energy efficiency. There are two ways to recover engine waste heat: organic Rankine cycle [75] and thermoelectric generator [76]. Based on the Seebeck effect, a thermoelectric generator generates electricity when there is a thermal gradient across the junctions of two dissimilar materials. The organic Rankine cycle is preferred to a thermoelectric generator, taking into account conversion efficiency, technology maturity and cost. It is estimated that organic Rankine cycle has an efficiency of up to around 15\% [75,77]. A typical organic Rankine cycle system with an EM (generator) is illustrated in Figure 13. The working fluid absorbs heat from engine exhaust gases. Expansion of vaporized fluid generates mechanical power, which is transformed into electrical power and stored in the battery. The recovered energy would downsize the battery pack. 


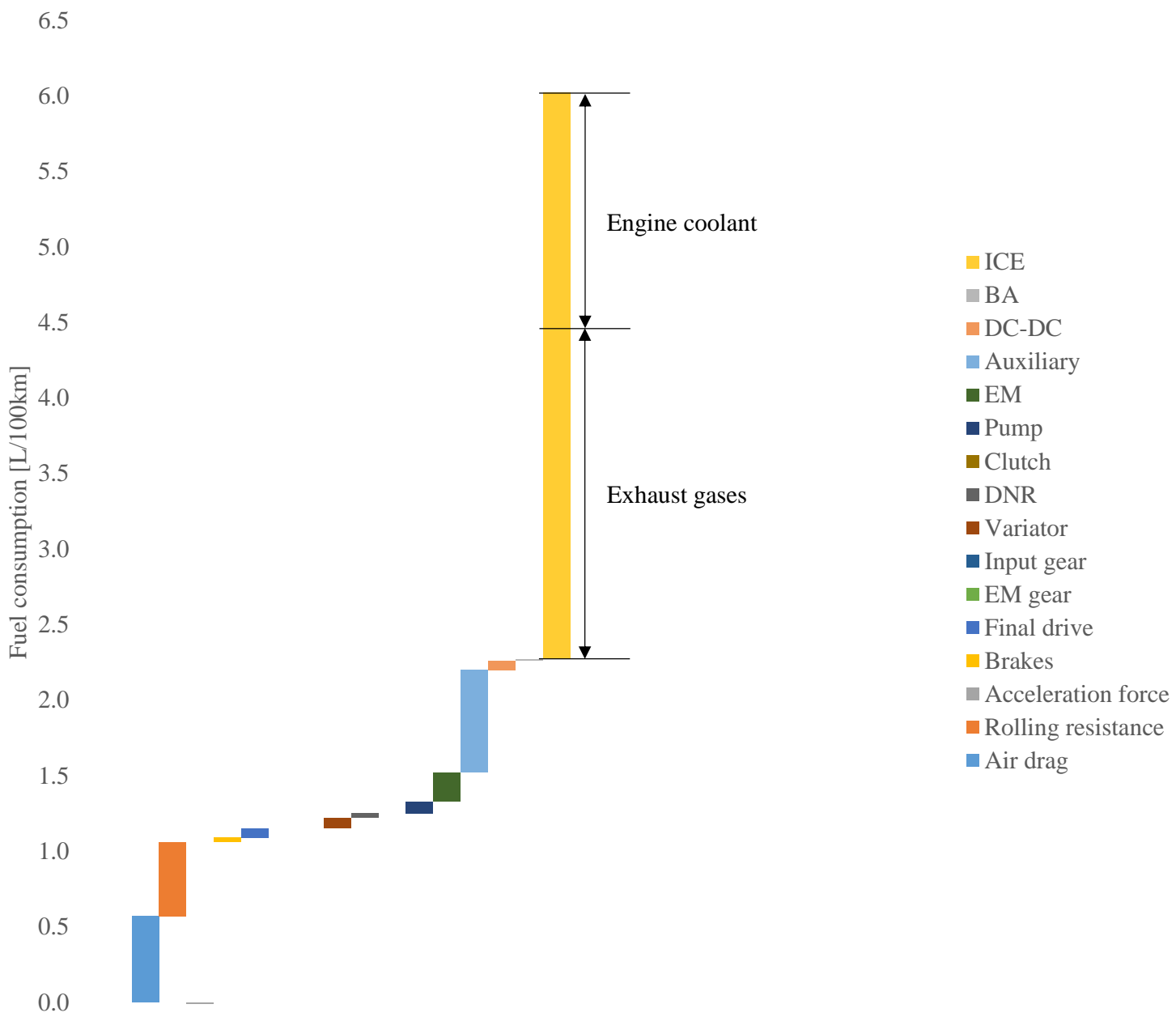

Figure 12. Typical energy balance of an HEV in charge sustaining mode [74], where DC-DC represents the DC to DC converter and DNR the drive, neutral and reverse set.

Typically, in an HEV (Figure 12), auxiliaries, e.g., cabin heating, consume a large amount of energy. It is apparent that electric heaters powered by the battery fail to provide an optimal solution. Owing to higher coefficient of performance, a heat pump can be employed instead [78]. While conventionally a heat pump only extracts heat from ambient air, substantial waste heat from the electric drive, as shown in Figure 14 [79], can also be used to boost heating performance, resulting in a decrease in battery load and an increase in driving range. As reported in [80], the coefficient of performance and heating capacity can be increased by around $9.3 \%$ and $31.5 \%$, respectively, by utilizing the waste heat from ambient and electric devices. Besides, as is made evident by Figure 7, transmission and electric drive have similar temperature levels, which could be combined together with a single cooling loop [81]. This would contribute to the heat that can be recovered by heat pump, leading to an improved heating performance. The electric drive and transmission cooling circuit exchange heat with the refrigerant circuit and cabin to improve the heating performance, as demonstrated in Figure 15. 


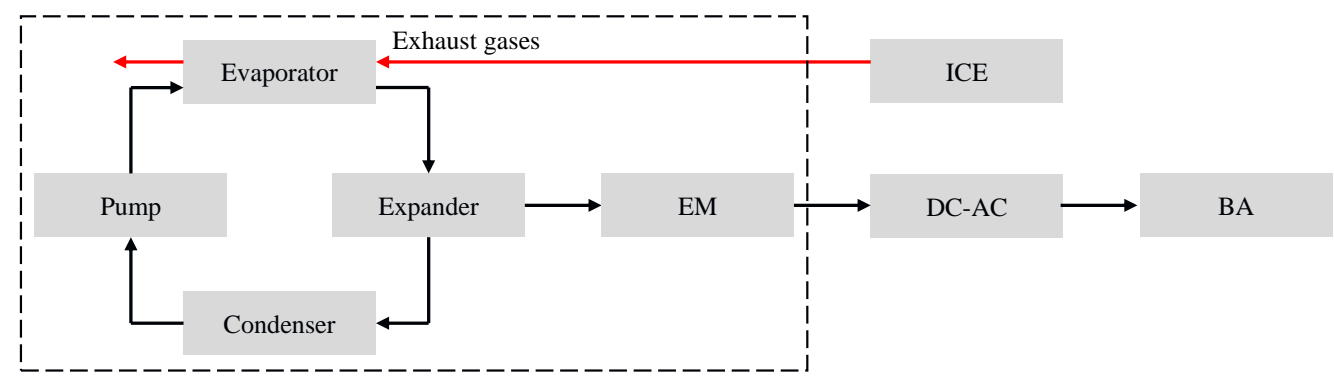

Figure 13. Organic Rankine cycle.

Note that design and control of the organic Rankine cycle system and heat pump system have yet to be integrated at system level to identify the energy savings. A detailed cost-benefit analysis would also be required before mass production of these systems.

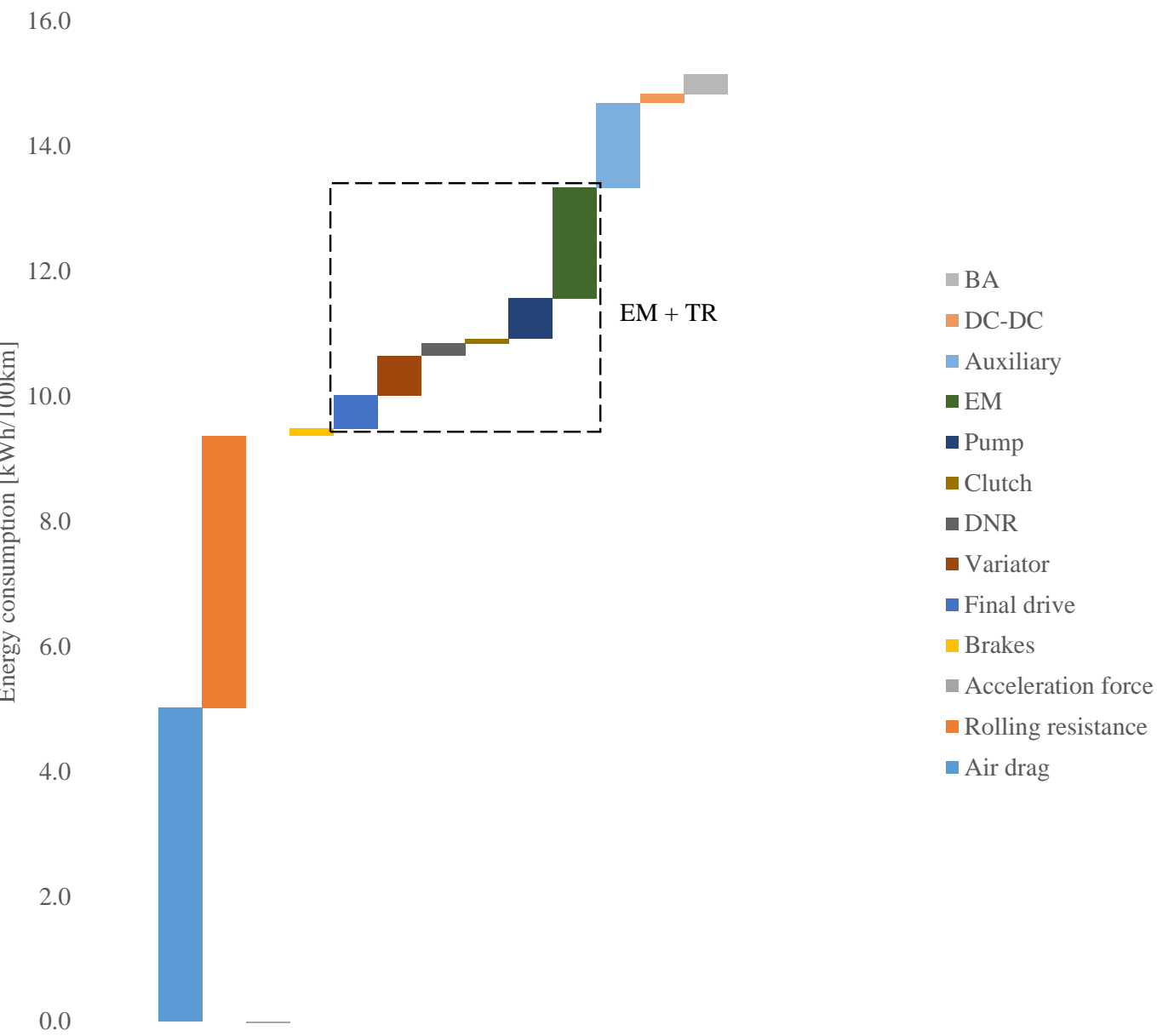

Figure 14. Typical energy balance of an HEV in charge depleting mode. Reprint with permission [79]; 2019, Elsevier. 


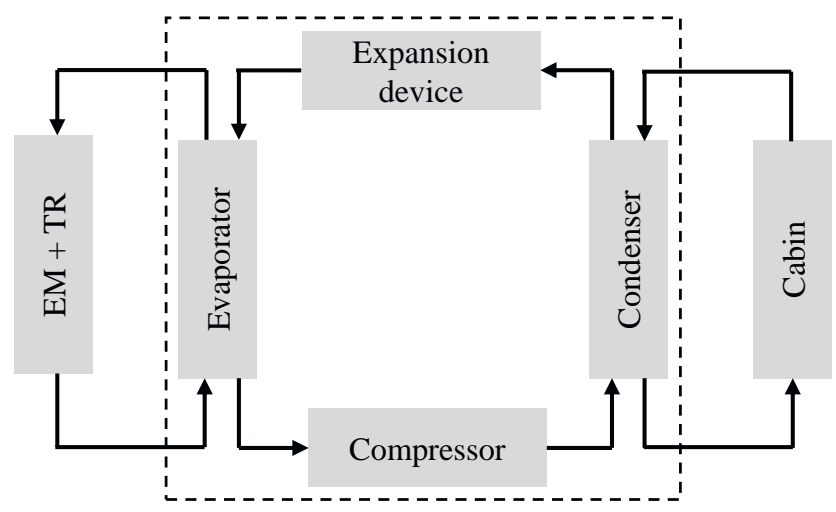

Figure 15. Heat pump system using waste heat from electric drive and transmission.

\subsection{Heat Exchange}

At low temperatures, the engine has higher frictional losses because of increased hydrodynamic effects and poor combustion. The difference in fuel consumption between a warm engine and a cold one is around $12 \%$ [82]. The battery performance deteriorates remarkably at low temperatures, which has negative impacts on reliability, safety and efficiency. Due to cabin heating, the driving range of an EV can be reduced by up to around 68\% [83]. It can be observed from Figure 12 that the heat energy transferred to the engine coolant is significant, which can be utilized to heat up lubrication oils, the cabin, the battery and so on [84]. As shown in Figure 16, where electrified actuators are used, engine coolant is utilized to warm up engine oil, transmission oil and the cabin's heater core using a three-way valve. It is reported that powertrain efficiency can be improved by around $4 \%$ due to fast warm-up [84].

Additionally, as illustrated in Figure 14, in EV mode, the electric drive and transmission coolant can be utilized to heat up the engine and battery during cold-start conditions to reduce power dissipation. Overall, the heat exchange between powertrain components can be summarized in Figure 17. Assume each cooling circuit is self-contained, consisting of heat source, fluid delivery device and heat sink. However, optimal control strategies are needed to allocate and remove heat effectively, which would increase efficiency and reduce the thermal system size and cost.

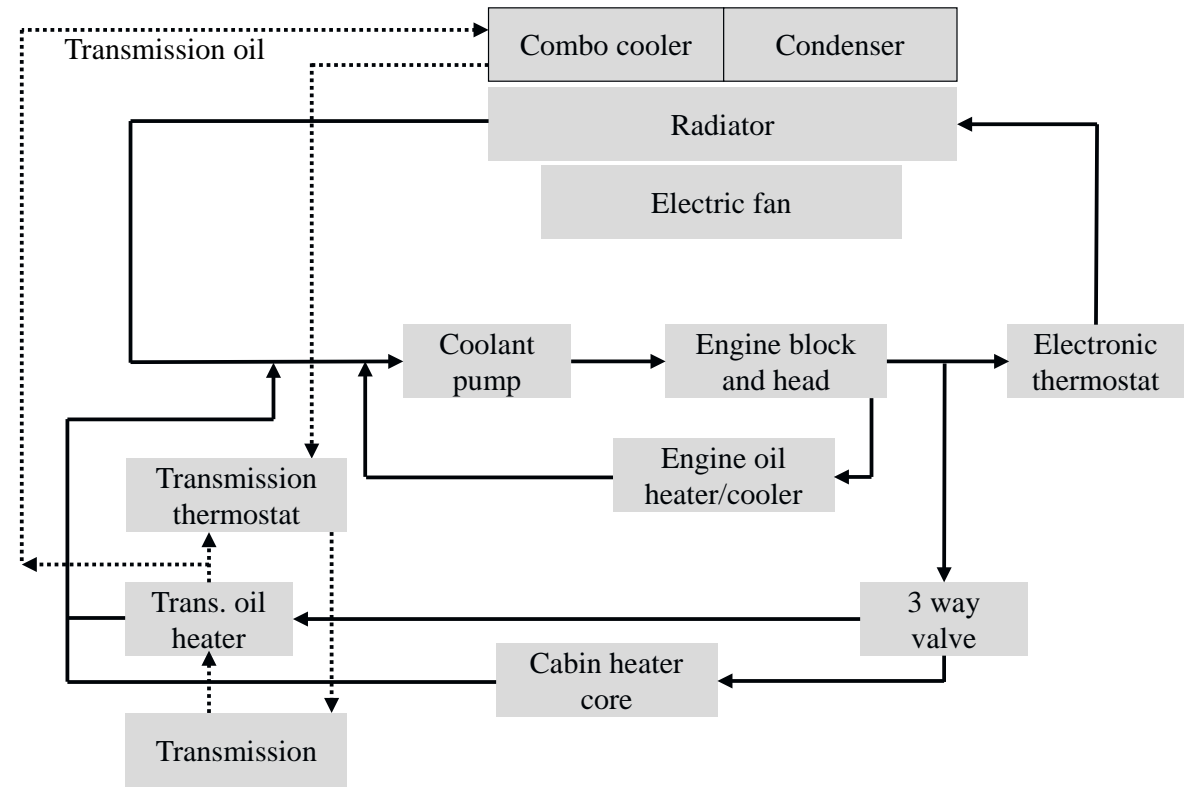

Figure 16. Heat energy distribution between powertrain components [84]. 


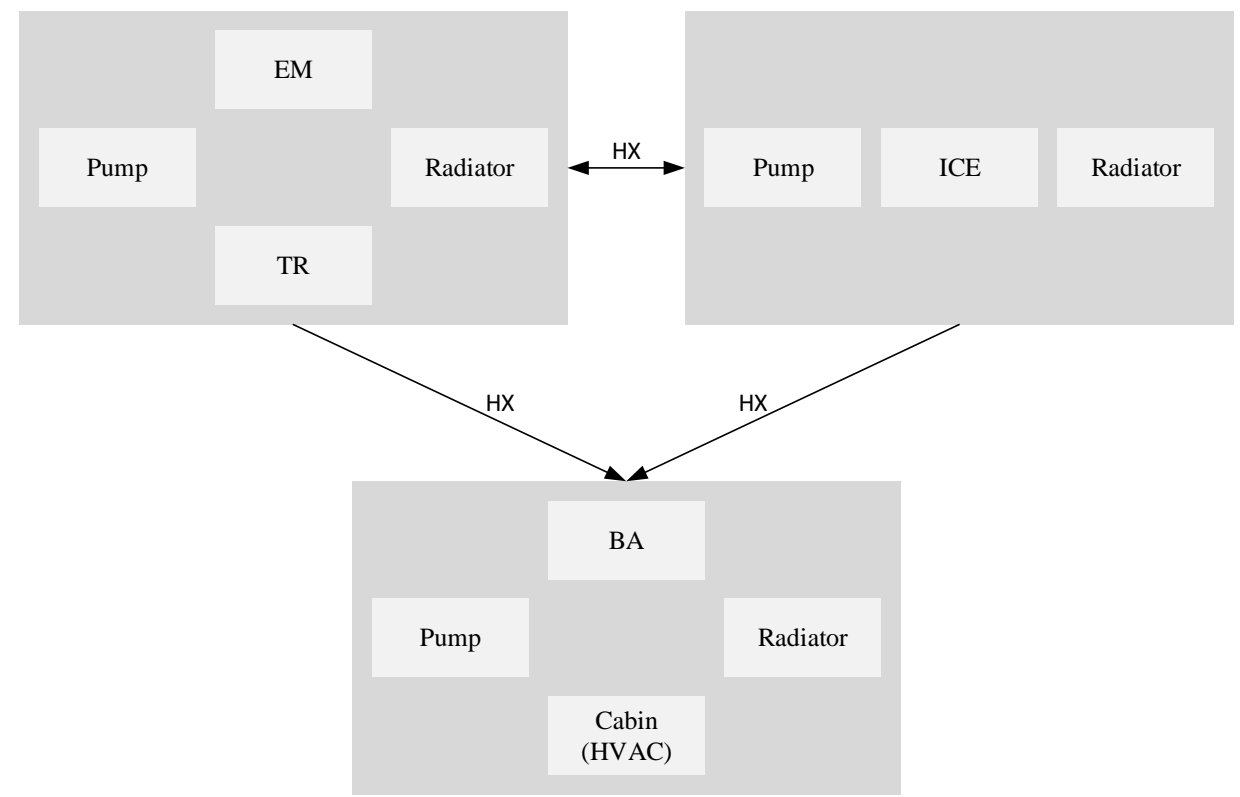

Figure 17. Heat exchange between electrified powertrain components, where HX represents the heat exchanger.

\subsection{Transition to Electric Vehicles}

In the electrification of vehicles, the first front is HEVs. They have played a pivotal role in reducing energy consumption in the past decades. Nowadays, EVs have a greater positive impact on the environment compared to HEVs, which has accelerated EVs' resurgence. There exist a variety of EV architectures, depending on the transmission type, the number of EMs and their locations [85]. Even though single-speed transmissions currently dominate the EV market, research on multi-speed transmissions, such as two-speed ones and continuously variable transmission (CVT), is emerging, focusing on cost function optimization, energy efficiency and vehicle performance [86]. For example, depending on loading conditions, e.g., hill climbing, EVs would benefit from various operational states provided by a CVT without torque interruption. In this respect, the integration of things such as the EM and the transmission, plays an important role. As shown in [87], a CVT could provide opportunities of optimizing the EM due to continuous ratio adjustment. In turn, the wider constant power region of the EM could help in the optimization of the CVT. These would result in an optimized battery and an optimized thermal system. Finding optimal component sizes and letting the system operate at high efficiency would contribute to cost function reduction. Optimal thermal management with electrified actuators also contributes to reducing the size and cost of the thermal system. Additionally, if waste heat from the electric drive and transmission is used in an EV, the sizes of the heat pump and the battery pack can be reduced.

\subsection{Plant Design}

For sizing of powertrain components, current studies mainly focus on OB methods (Figure 5), such as the widely used PSO [88]. Limited research can be found in terms of applying OB algorithms to determining the thermal system size. Moreover, to arrive at an optimal system design, component sizing needs to be coupled with the control layer. Generally, in terms of optimality, nested and simultaneous approaches outperform sequential and iterative ones. Simultaneous methods that require convex features of a system are computationally more efficient than nested schemes relying on exhaustive search. Recent studies mostly concentrate on nested and simultaneous schemes because of optimality. Each method has its own strengths and limitations. For example, to find optimal energy management and component sizes of a series PHEV, two methods were employed in [89], where CP represents the simultaneous coordination scheme and PSO/DP represents the nested approach. In [89], 
the same optimal solution was obtained, which achieved a fuel efficiency improvement of around $10.4 \%$ compared to the initial powertrain design. CP delivered superior performance to PSO by a factor of 20 in terms of computation time. Tuning for PSO is also required. Nevertheless, heuristics or DP are needed in $\mathrm{CP}$ to handle integer variables, e.g., engine on/off. Moreover, $\mathrm{CP}$ requires the problem to be solved in a convex form. To strike the balance between computation time and solution optimality, an iterative coordination method can be utilized, such as DP/CP [38]. The (close-to) optimal solution is then obtained in a considerably short time. Furthermore, topology dictates vehicle energy efficiency and cost. In order to choose a suitable configuration with large design space, topology generation has proven beneficial for design. However, current methods do not take into account the thermal management architecture, which may not yield an optimal system. Topology optimization needs to be integrated with size and control optimization so as to select the best configuration based on minimum TCO. Additionally, integrated design and control of a complete electrified vehicle considering both energy and thermal domains to reduce the TCO has yet to be addressed, while satisfying performance, driving comfort, passenger thermal comfort and reliability requirements.

\section{Conclusions}

This paper presents a comprehensive analysis of design (topology and size) and control optimization layers and coordination schemes for electrified vehicles, including energy and thermal domains. By combining those optimization layers, energy consumption and cost reductions can be obtained. Depending on the coupling and how sensitive the solution is to uncertainties in the design parameters, nested and simultaneous coordination methods outperform sequential and iterative ones with respect to solution optimality. Nested approaches are usually computationally heavy, whereas simultaneous ones often require convexification of the original problem. Energy and thermal management systems, which only started to appear recently, were thoroughly surveyed and classified into SETMSs and CETMSs. In CETMSs, control decisions are made only once at the supervisory level, which deliver superior performance to SETMSs in terms of energy savings. It was shown that there is a trade-off between optimality, computation time, causality and complexity. In order to further reduce $\mathrm{TCO}$, an analysis of future trends in terms of integrated design and control of electrified vehicles is presented, including employing WHR systems, exchanging heat between powertrain components and upgrading mechanical actuators.

Author Contributions: conceptualization, C.W.; methodology, C.W.; writing—original draft preparation, C.W.; writing-review and editing, T.H., E.I.C. and R.v.I.; supervision, T.H., E.I.C. and R.v.I.; All authors have read and agreed to the published version of the manuscript.

Funding: This research received no external funding.

Acknowledgments: This research was carried out under project number T18001 in the framework of the Research Program of the Materials innovation institute (M2i) (www.m2i.nl) supported by the Dutch government.

Conflicts of Interest: The authors declare no conflict of interest.

\section{Abbreviations}

The following abbreviations are used in this paper:

AC Air Conditioning

BA Battery

BER Brake Energy Recuperation

CAB Cabin

CAC Charge Air Cooler

CETMS Combined Energy and Thermal Management System

$\mathrm{CH} \quad$ Charging

$\mathrm{CP} \quad$ Convex Programming

CVT Continuously Variable Transmission

DC Direct Current 


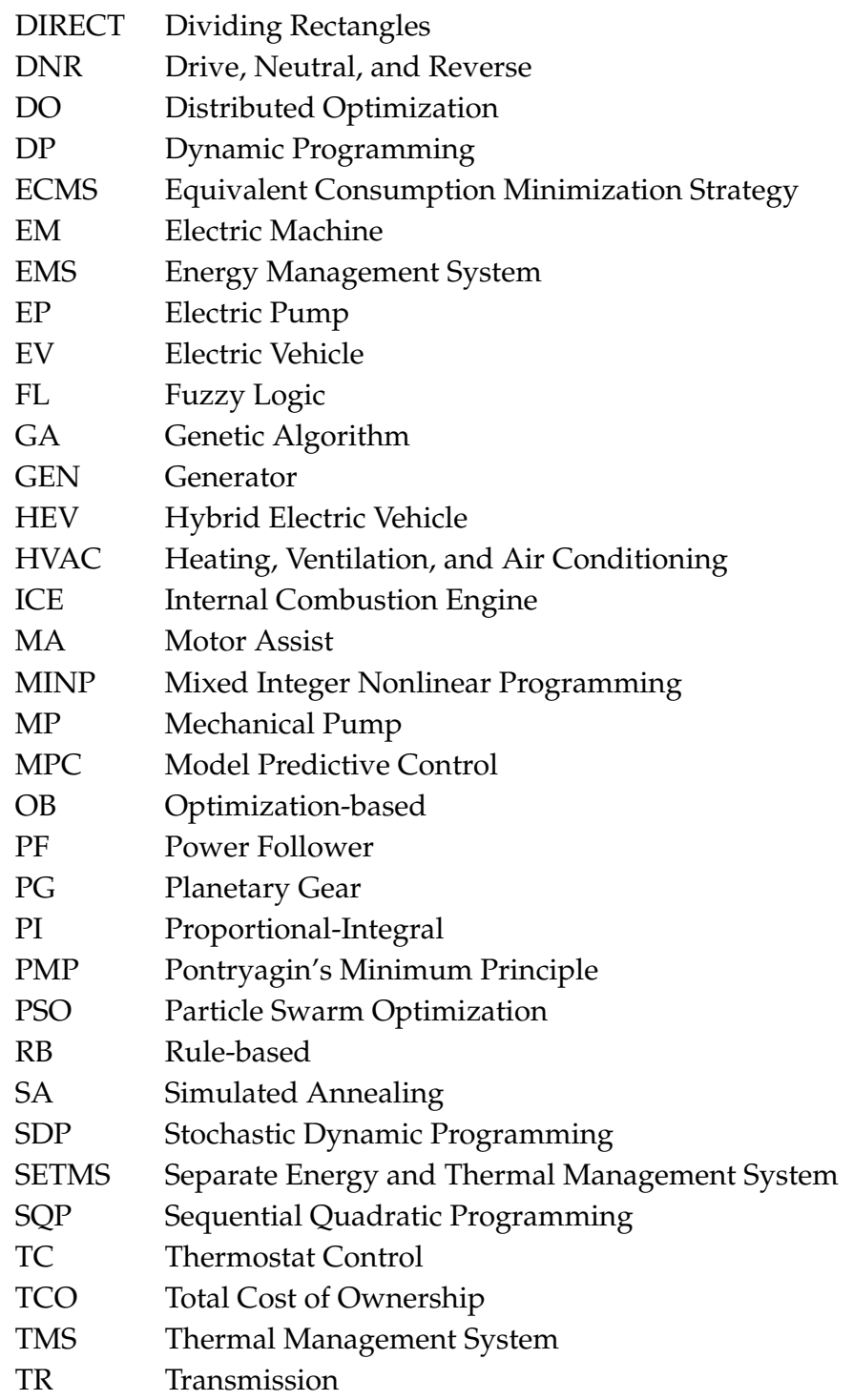

\section{References}

1. Yuan, R.; Fletcher, T.; Ahmedov, A.; Kalantzis, N.; Pezouvanis, A.; Dutta, N.; Watson, A.; Ebrahimi, K. Modelling and Co-simulation of Hybrid Vehicles: A Thermal Management Perspective. Appl. Therm. Eng. 2020, 180, 115883. [CrossRef]

2. Tao, X. Design, Modeling and Control of a Thermal Management System for Hybrid Electric Vehicles. Ph.D. Thesis, Clemson University, Clemson, SC, USA, 2016.

3. Shojaei, S.; McGordon, A.; Robinson, S.; Marco, J.; Jennings, P. Developing a Model for Analysis of the Cooling Loads of a Hybrid Electric Vehicle by Using Co-simulations of Verified Submodels. Proc. Inst. Mech. Eng. Part D J. Autom. Eng. 2018, 232, 766-784. [CrossRef]

4. Biswas, S. Thermal Management System and Performance Characteristics of Electric Vehicle; SAE Technical Paper 2020-28-0022; SAE International: Warrendale, PA, USA, 2020.

5. Amini, M.R.; Kolmanovsky, I.; Sun, J. Hierarchical MPC for Robust Eco-cooling of Connected and Automated Vehicles and Its Application to Electric Vehicle Battery Thermal Management. IEEE Trans. Control Syst. Technol. 2020, 1-13. [CrossRef]

6. Lei, Z.; Qin, D.; Hou, L.; Peng, J.; Liu, Y.; Chen, Z.A. Adaptive Equivalent Consumption Minimization Strategy for Plug-in Hybrid Electric Vehicles based on Traffic Information. Energy 2020, 190. [CrossRef]

7. Afzal, A.; Mohammed Samee, A.D.; Abdul Razak, R.K.; Ramis, M.K. Thermal management of Modern Electric Vehicle Battery Systems (MEVBS). J. Therm. Anal. Calorim. 2020. [CrossRef] 
8. Silvas, E.; Hofman, T.; Murgovski, N.; Etman, L.F.P.; Steinbuch, M. Review of Optimization Strategies for System-Level Design in Hybrid Electric Vehicles. IEEE Trans. Veh. Technol. 2017, 66, 57-70. [CrossRef]

9. Guzzella, L.; Sciarretta, A. Vehicle Propulsion Systems: Introduction to Modeling and Optimization, 2nd ed.; Springer: Berlin, Germany, 2010.

10. Zhuang, W.; Zhang, X.; Peng, H.; Wang, L. Simultaneous Optimization of Topology and Component Sizes for Double Planetary Gear Hybrid Powertrains. Energies 2016, 9, 411. [CrossRef]

11. Park, S. A Comprehensive Thermal Management System Model for Hybrid Electric Vehicles. Ph.D. Thesis, University of Michigan, Ann Arbor, MI, USA, 2011.

12. Liu, J.; Peng, H. A Systematic Design Approach for Two Planetary Gear Split Hybrid Vehicles. Veh. Syst. Dyn. 2010, 48, 1395-1412. [CrossRef]

13. Moura, S.J.; Callaway, D.S.; Fathy, H.K.; Stein, J.L. Tradeoffs between Battery Energy Capacity and Stochastic Optimal Power Management in Plug-in Hybrid Electric Vehicles. J. Power Sources 2010, 195, 2979-2988. [CrossRef]

14. Chan, C.C.; Bouscayrol, A.; Chen, K. Electric, Hybrid, and Fuel-cell Vehicles: Architectures and Modeling. IEEE Trans. Veh. Technol. 2010, 59, 589-598. [CrossRef]

15. Zhang, X.; Li, C.-T.; Kum, D.; Peng, H. Prius ${ }^{+}$and Volt ${ }^{-}$: Configuration Analysis of Power-Split Hybrid Vehicles with a Single Planetary Gear. IEEE Trans. Veh. Technol. 2012, 61, 3544-3552. [CrossRef]

16. Dagci, O.H.; Peng, H.; Grizzle, J.W. Hybrid Electric Powertrain Design Methodology with Planetary Gear Sets for Performance and Fuel Economy. IEEE Access 2018, 6, 9585-9602. [CrossRef]

17. Bayrak, A.E.; Kang, N.; Papalambros, P. Decomposition-based Design Optimization of Hybrid Electric Powertrain Arhitectures: Simultaneous Configuration and Sizing Design. J. Mech. Des. 2016, 138. [CrossRef]

18. Silvas, E.; Hofman, T.; Serebrenik, A.; Steinbuch, M. Functional and Cost-based Automatic Generator for Hybrid Vehicles Topologies. IEEE/ASME Trans. Mechatronics 2015, 20, 1561-1572. [CrossRef]

19. Johri, R.; Filipi, Z. Optimal Energy Management of a Series Hybrid Vehicle with Combined Fuel Economy and Low-emission Objectives. Proc. Inst. Mech. Eng. Part D J. Autom. Eng. 2014, 228, 1424-1439. [CrossRef]

20. Shabbir, W.; Evangelou, S.A. Threshold-changing Control Strategy for Series Hybrid Electric Vehicles. Appl. Energy 2019, 235, 761-775. [CrossRef]

21. Singh, K.V.; Bansal, H.O.; Singh, D. Feed-forward Modeling and Real-time Implementation of an Intelligent Fuzzy Logic-based Energy Management Strategy in a Series-parallel Hybrid Electric Vehicle to Improve Fuel Economy. Electr. Eng. 2020, 102, 967-987. [CrossRef]

22. Ehsani, M.; Gao, Y.; Emadi, A. Modern Electric, Hybrid Electric, and Fuel Cell Vehicles: Fundamentals, Theory, and Design, 2nd ed.; CRC: Boca Raton, FL, USA, 2010.

23. Vinot, E.; Trigui, R.; Cheng, Y.; Espanet, C.; Bouscayrol, A.; Reinbold, V. Improvement of an EVT-based HEV Using Dynamic Programming. IEEE Trans. Veh. Technol. 2014, 63, 40-50. [CrossRef]

24. Kim, N.; Cha, S.; Peng, H. Optimal Control of Hybrid Electric Vehicles based on Pontryagin's Minimum Principle. IEEE Trans. Control Syst. Technol. 2011, 19, 1279-1287.

25. Hadj-Said, S.; Colin, G.; Ketfi-Cherif, A.; Chamaillard, Y. Convex Optimization for Energy Management of Parallel Hybrid Electric Vehicles. IFAC-PapersOnLine 2016, 49, 271-276. [CrossRef]

26. Opila, D.F.; Wang, X.; McGee, R.; Grizzle, J.W. Real-time Implementation and Hardware Testing of a Hybrid Vehicle Energy Management Controller based on Stochastic Dynamic Programming. J. Dyn. Syst. Meas. Control 2013, 135. [CrossRef]

27. Nüesch, T.; Cerofolini, A.; Mancini, G.; Cavina, N.; Onder, C.; Guzzella, L. Equivalent Consumption Minimization Strategy for the Control of Real Driving NOx Emissions of a Diesel Hybrid Electric Vehicle. Energies 2014, 7, 3148-3178. [CrossRef]

28. Borhan, H.; Vahidi, A.; Phillips, A.M.; Kuang, M.L.; Kolmanovsky, I.V.; Di Cairano, S. MPC-based Energy Management of a Power-split Hybrid Electric Vehicle. IEEE Trans. Control Syst. Technol. 2012, 20, 593-603. [CrossRef]

29. Sundström, O.; Guzzella, L.; Soltic, L.P. Torque-assist Hybrid Electric Powertrain Sizing: From Optimal Control towards a Sizing Law. IEEE Trans. Control Syst. Technol. 2010, 18, 837-849. [CrossRef]

30. Pourabdollah, M.; Murgovski, N.; Grauers, A.; Egardt, B. Optimal Sizing of a Parallel Phev Powertrain. IEEE Trans. Veh. Technol. 2013, 62, 2469-2480. [CrossRef]

31. Sinoquet, D.; Rousseau, G.; Milhau, Y. Design Optimization and Optimal Control for Hybrid Vehicles. Optim. Eng. 2011, 12, 199-213. [CrossRef] 
32. Ma, C.; Ko, S.Y.; Jeong, K.Y.; Kim, H.S. Design Methodology of Component Design Environment for PHEV. Int. J. Automot. Technol. 2013, 14, 785-795. [CrossRef]

33. Patil, R.; Adornato, B.; Filipi, Z. Design Optimization of a Series Plug-in Hybrid Electric Vehicle for Real-World Driving Conditions. SAE Int. J. Engines 2010, 3, 655-665. [CrossRef]

34. Geller, B.; Bradley, T. Objective Comparison of Hybrid Vehicles through Simulation Optimization; SAE Technical Paper 2011-01-0943; SAE International: Warrendale, PA, USA, 2011.

35. Fang, L.; Qin, S.; Xu, G.; Li, T.; Zhu, K. Simultaneous Optimization for Hybrid Electric Vehicle Parameters based on Multi-objective Genetic Algorithms. Energies 2011,4, 532-544. [CrossRef]

36. Ebbesen, S.; Dönitz, C.; Guzzella, L. Particle Swarm Optimisation for Hybrid Electric Drive-train Sizing. Int. J. Veh. Des. 2012, 58, 181-199. [CrossRef]

37. Silvas, E. Integrated Optimal Design for Hybrid Electric Vehicles. Ph.D. Thesis, Eindhoven University of Technology, Eindhoven, The Netherlands, 2015.

38. Pourabdollah, M.; Murgovski, N.; Grauers, A.; Egardt, B.A. Iterative Dynamic Programming/Convex Optimization Procedure for Optimal Sizing and Energy Management of PHEVs. IFAC Proc. Vol. 2014, 47, 6606-6611. [CrossRef]

39. Sezer, V.; Gokasan, M.; Bogosyan, S. A Novel ECMS and Combined Cost Map Approach for High-efficiency Series Hybrid Electric Vehicles. IEEE Trans. Veh. Technol. 2011, 60, 3557-3570. [CrossRef]

40. Lee, H.; Song, C.; Kim, N.; Cha, S.W. Comparative Analysis of Energy Management Strategies for HEV: Dynamic Programming and Reinforcement Learning. IEEE Access 2020, 8, 67112-67123. [CrossRef]

41. Ebbesen, S. Optimal Sizing and Control of Hybrid Electric Vehicles. Ph.D. Thesis, ETH Zurich, Zurich, Switzerland, 2012.

42. Zhu, J.; Chen, L.; Wang, X.; Yu, L. Bi-level Optimal Sizing and Energy Management of Hybrid Electric Propulsion Systems. Appl. Energy 2020, 260, 114-134. [CrossRef]

43. Bianchi, D.; Rolando, L.; Serrao, L.; Onori, S.; Rizzoni, G.; Al-Khayat, N.; Hsieh, T.-M.; Kang, P. Layered Control Strategies for Hybrid Electric Vehicles based on Optimal Control. Int. J. Electr. Hybrid Veh. 2011, 3, 191-217. [CrossRef]

44. Hofman, T.; Ebbesen, S.; Guzzella, L. Topology Optimization for Hybrid Electric Vehicles with Automated Transmissions. IEEE Trans. Veh. Technol. 2012, 6, 2442-2451. [CrossRef]

45. Nüesch, T.; Ott, T.; Ebbesen, S.; Guzzella, L. Cost and Fuel-Optimal Selection of HEV Topologies using Particle Swarm Optimization and Dynamic Programming. In Proceedings of the 2012 American Control Conference, Montreal, QC, Canada, 27-29 June 2012.

46. Bennion, K.; Thornton, M. Integrated Vehicle Thermal Management for Advanced Vehicle Propulsion Technologies; Technical Report; National Renewable Energy Laboratory: Golden, CO, USA, 2010.

47. Fletcher, T.; Kalantzis, N.; Ahmedov, A.; Yuan, R.; Ebrahimi, K.; Dutta, N.; Price, C. Holistic Thermal Energy Modelling for Full Hybrid Electric Vehicles (HEVs); SAE Technical Paper 2020-01-0151; SAE International: Warrendale, PA, USA, 2020.

48. Tao, X.; Wagner, J. A Thermal Management System for the Battery Pack of a Hybrid Electric Vehicle: Modeling and Control. Proc. Inst. Mech. Eng. Part D J. Automob. Eng. 2016, 230, 190-201. [CrossRef]

49. Tao, X.; Zhou, K.; Wagner, J.; Hofmann, H.A. Electric Motor Thermal Management System for Hybrid Vehicles: Modelling and Control. Int. J. Veh. Perform. 2016, 2, 207-227.

50. Zhang, X.; Ivanco, A.; Tao, X.; Wagner, J.; Filipi, Z. Optimization of the Series-hev Control with Consideration of the Impact of Battery Cooling Auxiliary Losses. SAE Int. J. Altern. Power 2014, 3, 234-243. [CrossRef]

51. Wang, T.; Jagarwal, A.; Wagner, J.R.; Fadel, G. Optimization of an Automotive Radiator Fan Array Operation to Reduce Power Consumption. IEEE/ASME Trans. Mechatronics 2015, 20, 2359-2369. [CrossRef]

52. Lopez-Sanz, J.; Ocampo-Martinez, C.; Álvarez-Flórez, J.; Moreno-Eguilaz, M.; Ruiz-Mansilla, R.; Kalmus, J.; Gräeber, M.; Lux, G. Thermal Management in Plug-in Hybrid Electric Vehicles: A Real-time Nonlinear Model Predictive Control Implementation. IEEE Trans. Veh. Technol. 2017, 66, 7751-7760. [CrossRef]

53. Saha, J.; Chen, H.; Rahman, S. Model based Design and Optimization of Vehicle Thermal Management System; SAE Technical Paper 2016-01-0283; SAE International: Warrendale, PA, USA, 2016.

54. Hughes, C.; Wiseman, M. Feasibility of Intelligent Control Strategies to Reduce Cooling System Size; SAE Technical Paper 2001-01-1759; SAE International: Warrendale, PA, USA, 2001. 
55. Johnson, R.W.; Evans, J.L.; Jacobsen, P.; Thompson, J.R.; Christopher, M. The Changing Automotive Environment: High-Temperature Electronics. IEEE Trans. Electron. Packag. Manuf. 2004, 27, 164-176. [CrossRef]

56. Cho, H.; Jung, D.; Filipi, Z.; Assanis, D.N.; Vanderslice, J.; Bryzik, W. Application of Controllable Electric Coolant Pump for Fuel Economy and Cooling Performance Improvement. J. Eng. Gas Turbines Power 2007, 129, 239-244. [CrossRef]

57. Park, S.; Kokkolaras, M.; Malikopoulos, A.; AbdulNour, B.; Sedarous, J.; Jung, D. Thermal Management System Modeling and Optimization for Heavy Hybrid Electric Military Vehicles. In Proceedings of the 2010 NDIA Ground Vehicle Systems Engineering and Technology Symposium, Dearborn, MI, USA, 17-19 August 2010.

58. Tao, X.; Wagner, J. Optimization of a Military Ground Vehicle Engine Cooling System Heat Exchanger-Modeling and Size Scaling; SAE Technical Paper 2017-01-0259; SAE International: Warrendale, PA, USA, 2017.

59. Park, S.; Jung, D. Design of Vehicle Cooling System Architecture for a Heavy Duty Series-hybrid Electric Vehicle Using Numerical System Simulations. J. Eng. Gas Turbines Power 2010, 132. [CrossRef]

60. Wei, C.; Hofman, T.; Ilhan Caarls, E.; van Iperen, R. Evolution and Classification of Energy and Thermal Management Systems in Electrified Powertrains. In Proceedings of the 2019 IEEE Vehicle Power and Propulsion Conference, Hanoi, Vietnam, 14-17 October 2019.

61. Zhang, X. Supervisory Control Optimization for a Series Hybrid Electric Vehicle with Consideration of Battery Thermal Management and Aging. Ph.D. Thesis, Clemson University, Clemson, SC, USA, 2016.

62. Pham, T.H. Integrated Energy and Battery Life Management for Hybrid Vehicles. Ph.D. Thesis, Eindhoven University of Technology, Eindhoven, The Netherlands, 2015.

63. Jiménez-Espadafor, F.J.; Guerrero, D.P.; Trujillo, E.C.; García, M.T.; Wideberg, J. Fully Optimized Energy Management for Propulsion, Thermal Cooling and Auxiliaries of a Serial Hybrid Electric Vehicle. Appl. Therm. Eng. 2015, 91, 694-705. [CrossRef]

64. Romijn, T.C.J.; Donkers, M.C.F.; Kessels, J.T.B.A.; Weiland, S. A Distributed Optimization Approach for Complete Vehicle Energy Management. IEEE Trans. Control Syst. Technol. 2019, 27, 964-980. [CrossRef]

65. Pham, T.H.; Kessels, J.T.B.A.; van den Bosch, P.P.J.; Huisman, R.G.M.; Nevels, R.M.P.A. On-line Energy and Battery Thermal Management for Hybrid Electric Heavy-Duty Truck. In Proceedings of the 2013 American Control Conference, Washington, DC, USA, 17-19 June 2013.

66. Ngo, V.; Hofman, T.; Steinbuch, M.; Serrarens, A. Optimal Control of the Gearshift Command for Hybrid Electric Vehicles. IEEE Trans. Veh. Technol. 2012, 61, 3531-3543. [CrossRef]

67. Nüesch, T.; Elbert, P.; Flankl, M.; Onder, C.; Guzzella, L. Convex Optimization for the Energy Management of Hybrid Electric Vehicles Considering Engine Start and Gearshift Costs. Energies 2014, 7, 834-856. [CrossRef]

68. Böhme, T.J.; Frank, B. Hybrid Systems, Optimal control and Hybrid Vehicles: Theory, Methods and Applications; Springer: Cham, Switzerland, 2017.

69. Tate, E.D.; Grizzle, J.W.; Peng, H. SP-SDP for Fuel Consumption and Tailpipe Emissions Minimization in an EVT Hybrid. IEEE Trans. Control Syst. Technol. 2010, 18, 673-687. [CrossRef]

70. Serrao, L.; Onori, S.; Sciarretta, A.; Guezennec, Y.; Rizzoni, G. Optimal Energy Management of Hybrid Electric Vehicles Including Battery Aging. In Proceedings of the 2011 American Control Conference, San Francisco, CA, USA, 29 June-1 July 2011.

71. Barbarisi, O.; Westervelt, E.R.; Vasca, F.; Rizzoni, G. Power Management Decoupling Control for a Hybrid Electric Vehicle. In Proceedings of the 44th IEEE Conference on Decision and Control, Seville, Spain, 12-15 December 2005.

72. Wang, T.; Wagner, J. A Smart Engine Cooling System-Experimental Study of Integrated Actuator Transient Behavior; SAE Technical Paper 2015-01-1604; SAE International: Warrendale, PA, USA, 2015.

73. Tao, X.; Zhou, K.; Ivanco, A.; Wagner, J.; Hofmann, H.; Filipi, Z. A Hybrid Electric Vehicle Thermal Management System-Nonlinear Controller Design; SAE Technical Paper 2015-01-1710; SAE International: Warrendale, PA, USA, 2015.

74. Wei, C.; Hofman, T.; Ilhan Caarls, E.; van Iperen, R. Integrated Energy and Thermal Management for Electrified Powertrains. Energies 2019, 12, 2058. [CrossRef]

75. Wang, T.; Zhang, Y.; Peng, Z.; Shu, G. A Review of Researches on Thermal Exhaust Heat Recovery with Rankine Cycle. Renew. Sustain. Energy Rev. 2011, 15, 2862-2871. [CrossRef] 
76. Martins, J.; Goncalves, L.M.; Antunes, J.; Brito, F.P. Thermoelectric Exhaust Energy Recovery with Temperature Control through Heat Pipes. In Proceedings of the SAE 2011 World Congress \& Exhibition, Detroit, MI, USA, 12-14 April 2011.

77. Merz, F.; Sciarretta, A.; Dabadie, J.-C.; Serrao, L.O. the Optimal Thermal Management of Hybrid-electric Vehicles with Heat Recovery Systems. Oil Gas Sci. Technol. 2012, 67, 601-612. [CrossRef]

78. Qi, Z. Advances on Air Conditioning and Heat Pump System in Electric Vehicles-A Review. Renew. Sustain. Energy Rev. 2014, 38, 754-764. [CrossRef]

79. Wei, C.; Hofman, T.; Ilhan Caarls, E.; van Iperen, R. Energy-efficiency Improvement Potential of Electric Vehicles Considering Transmission Temperature. IFAC-PapersOnLine 2019, 52, 211-216. [CrossRef]

80. Ahn, J.H.; Kang, H.; Lee, H.S.; Jung, H.W.; Baek, C.; Kim, Y. Heating Performance Characteristics of a Dual Source Heat Pump using Air and Waste Heat in Electric Vehicles. Appl. Energy 2014, 119, 1-9. [CrossRef]

81. McFadden, C.; Hughes, K.; Raser, L.; Newcomb, T. Electrical Conductivity of New and Used Automatic Transmission Fluids. SAE Int. J. Fuels Lubr. 2016, 9, 519-526. [CrossRef]

82. Dubouil, R.; Hetet, J.F.; Maiboom, A. Modelling of the Warm-up of a Spark Ignition Engine: Application to Hybrid Vehicles. In Proceedings of the SAE International Powertrains, Fuels and Lubricants Meeting, Kyoto, Japan, 30 August-2 September 2011. [CrossRef]

83. Titov, G.; Lustbader, J. Modeling Control Strategies and Range Impacts for Electric Vehicle Integrated Thermal Management Systems with MATLAB/Simulink; SAE Technical Paper 2017-01-0191; SAE International: Warrendale, PA, USA, 2017. [CrossRef]

84. Laboe, K.; Canova, M. Powertrain Waste Heat Recovery: A Systems Approach to Maximize Drivetrain Efficiency. In Proceedings of the ASME 2012 Internal Combustion Engine Division Spring Technical Conference, Torino, Italy, 6-9 May 2012.

85. Tie, S.F.; Tan, C.W. A Review of Energy Sources and Energy Management System in Electric Vehicles. Renew. Sustain. Energy Rev. 2013, 20, 82-102.

86. Hofman, T.; Janssen, N.H.J. Integrated Design Optimization of the Transmission System and Vehicle Control for Electric Vehicles. IFAC-PapersOnLine 2017, 50, 10072-10077.

87. van der Sluis, F.; Römers, L.; van Spijk, G.; Hupkes, I. CVT, Promising Solutions for Electrification; SAE Technical Paper 2019-01-0359; SAE International: Warrendale, PA, USA, 2019. [CrossRef]

88. Scholl, M.; Minnerup, K.; Reiter, C.; Bernhardt, B.; Weisbrodt, E.; Newiger, S. Optimization of a Thermal Management System for Battery Electric Vehicles. In Proceedings of the 2019 Fourteenth International Conference on Ecological Vehicles and Renewable Energies (EVER), Monte-Carlo, Monaco, 8-10 May 2019. [CrossRef]

89. Pourabdollah, M.; Silvas, E.; Murgovski, N.; Steinbuch, M.; Egardt, B. Optimal Sizing of a Series PHEV: Comparison between Convex Optimization and Particle Swarm Optimization. IFAC-PapersOnLine 2015, $48,16-22$.

Publisher's Note: MDPI stays neutral with regard to jurisdictional claims in published maps and institutional affiliations.

(C) 2020 by the authors. Licensee MDPI, Basel, Switzerland. This article is an open access article distributed under the terms and conditions of the Creative Commons Attribution (CC BY) license (http:/ / creativecommons.org/licenses/by/4.0/). 